\title{
Reduced Microglial Activity and Enhanced Glutamate Transmission in the Basolateral Amygdala in Early CNS Autoimmunity
}

\author{
Shaona Acharjee, ${ }^{1}$ Megan Verbeek, ${ }^{2}$ Carlos D. Gomez, ${ }^{1}$ CKanchan Bisht,${ }^{3}$ Benjamin Lee, ${ }^{1}$ Lucas Benoit, ${ }^{1}$ \\ Keith A. Sharkey, ${ }^{1}$ Adrienne Benediktsson, ${ }^{2}{ }^{-}$Marie-Eve Tremblay, ${ }^{3}$ and ${ }^{\circledR}$ Quentin J. Pittman $^{1}$ \\ ${ }^{1}$ Hotchkiss Brain Institute, University of Calgary, Calgary, Alberta T2N 4N1, Canada, ${ }^{2}$ Department of Biology, Mount Royal University, Calgary, Alberta, \\ T3E 6K6, Canada, and ${ }^{3}$ Department of Molecular Medicine, Université Laval, Quebec City, Quebec, G1V 4G2, Canada
}

Emotional dysfunction is common in multiple sclerosis (MS) patients and in mouse models of MS, including experimental autoimmune encephalomyelitis (EAE); however, the etiology of these behaviors is poorly understood. To identify CNS changes associated with these behaviors, we focused on the basolateral amygdala (BLA) because of its central role in the regulation of emotional behavior. Whole-cell recordings were performed in the principal neurons of the BLA in early EAE, before demyelination, T-cell invasion, and motor dysfunction. EAE female mice displayed increased frequency of mEPSCs, with no alteration in amplitude or evoked EPSC paired-pulse ratio compared with controls. We found an increase in the AMPA-NMDA ratio and dendritic spine density, indicating increased numbers of glutamatergic synapses. We saw similar electrophysiological changes in BLA principal neurons after microglia were either inactivated (minocycline) or depleted (Macl-Saporin) in the BLA. Microglia regulate synapses through pruning, directed by complement protein 3 (C3) expression. C3 was downregulated in the BLA in EAE. Ultrastructural analysis of microglia revealed more complex ramifications and reduced extracellular digestion of cellular elements. We also observed reduced IBA-1 and CD68 staining and lack of proinflammatory cytokine expression in the amygdala. Thus, early EAE is a state of microglial "deactivation" associated with reduced synaptic pruning. This contrasts with the prototypic microglial activation commonly associated with inflammatory CNS disease. Additionally, these data support a role for the acquired immune system to influence both neuronal and microglial function in early CNS autoimmunity.

Key words: AMPA; amygdala; dendritic spine; EAE; microglia; multiple sclerosis

Significance Statement

Microglia help regulate synaptic homeostasis, but there has been little evidence for how this might be important in neuroinflammatory diseases. The data from this study reveal increased synaptic activity and spine density in early stages of experimental autoimmune encephalomyelitis (an animal model of multiple sclerosis) in the basolateral amygdala, a nucleus important in the types of behavioral changes we have previously described. These electrophysiological and morphological effects occurred without significant elevation of local inflammatory cytokines or local demyelination. Unexpectedly, in the context of inflammatory state, we found that microglia were "deactivated." This study provides strong evidence for a link between microglial activity and synaptic function; the conclusions contrast with the generally accepted view that microglia are activated in inflammatory disease.

\section{Introduction}

Multiple sclerosis (MS) is an autoimmune inflammatory disorder of the CNS in which myelin specific T-cells destroy the myelin

\footnotetext{
Received Feb. 12, 2018; revised Aug. 27, 2018; accepted Aug. 29, 2018.

Author contributions: S.A. wrote the first draft of the paper; S.A., K.B., K.A.S., A.B., M.-E.T., and Q.J.P. edited the paper; S.A., C.D.G., K.A.S., A.B., and Q.J.P. designed research; S.A., M.V., K.B., B.L., L.B., and M.-E.T. performed research; B.L. contributed unpublished reagents/analytic tools; S.A., M.V., C.D.G., K.B., A.B., and M.-E.T. analyzed data.

These studies were supported by the Canadian Institutes of Health Research, Alberta Innovates Health Solutions, Cumming School of Medicine Research Enhancement Program to Q.J.P. and K.A.S., Live Cell Imaging Resources Laboratory, University of Calgary, Natural Sciences and Engineering Research Council of Canada to M.-E.T., and
}

sheath, leading to demyelination and consequent motor and sensory impairment. Several behavioral comorbidities, such as anx-

Mount Royal University to A.B. as well as salary awards from the Alberta Heritage Foundation for Medical Research to Q.J.P., CONACYT-Mexican Council of Science and Technology to C.D.G., and Fonds de recherche en Santé Quebec to M.-E.T. K.A.S. is the Crohn's and Colitis Canada Chair in IBD Research at the University of Calgary. M.-E.T. is Canada Research Chair (Tier 2) in Neuroimmune Plasticity in Health and Therapy. We thank Mio Tsutsui, Kaushik Sharma, and Kristin Milloy for technical support; and Drs. Tuan Trang and William F. Colmers for comments on the manuscript. The authors declare no competing financial interests.

Correspondence should be addressed to Dr. Quentin J. Pittman, Hotchkiss Brain Institute, Department of Physiology and Pharmacology, University of Calgary, Calgary, Alberta T2N 4N1, Canada. E-mail: pittman@ucalgary.ca.

https://doi.org/10.1523/JNEUROSCI.0398-18.2018

Copyright $\odot 2018$ the authors $\quad 0270-6474 / 18 / 389019-15 \$ 15.00 / 0$ 
iety, depression, and other mood disorders, commonly occur in MS (Feinstein, 2011). Almost 1 in 2 MS patients will experience clinically significant depression in their lifetime (an overall lifetime frequency of $25 \%-50 \%$ ), which is 3 times the prevalence in the general population (Feinstein et al., 2014). These comorbidities often do not correlate with physical impairments and may precede the sensory and motor symptoms associated with MS.

Experimental autoimmune encephalomyelitis (EAE) is an animal model of MS that exhibits several of its cardinal features, including motor paralysis, hyperalgesia and allodynia, demyelination, and inflammation in the CNS (Constantinescu et al., 2011). EAE animals develop changes in anxiety-like and coping behaviors, and in fear memory, even before the onset of motor symptoms (Pollak et al., 2002; Haji et al., 2012; Acharjee et al., 2013). These behavioral changes are associated with increased plasma corticosterone and hypothalamic $T N F-\alpha$ and $I L-1 \beta$ transcripts, inflammatory changes within the CNS that are associated with various sickness behaviors (D'Mello et al., 2013). It is therefore likely that the presence of CNS inflammation may be responsible for the behavioral changes in MS (or EAE).

Microglia are the resident myeloid cells of the brain (Sierra et al., 2014) and are thought to mediate the first response to inflammatory signals. In addition, microglial interactions with synapses are important in maintenance of neuronal connections and affect neuronal plasticity (Wake et al., 2009; Tremblay et al., 2010a). In healthy and developing brains, microglia prune synapses at both presynaptic and postsynaptic sides and thus regulate synaptic innervation (Paolicelli et al., 2011; Schafer et al., 2012). Recently, a crucial role for microglial autophagy in synaptic pruning has been demonstrated (Kim et al., 2017). The molecular cues that guide microglia to the synapses destined for engulfment remain to be identified, as do the specific mechanisms that are recruited. However, it is thought that the complement factors C1 and C3 'tag' such synapses and thus direct the microglia to them for phagocytosis (Schafer et al., 2012; Bialas and Stevens, 2013). In addition, synaptic stripping, which is the physical separation of presynaptic and postsynaptic elements by intervening microglial processes, is well documented upon injury (Kettenmann et al., 2013).

The current work investigated the etiology of early CNS changes in the autoimmune inflammatory model, EAE. The experimental animals received the antigen, myelin antigen $\left(\mathrm{MOG}_{35-55}\right)$ in pertussis toxin/complete Freund's adjuvant (CFA), whereas the control animals received pertussis toxin/CFA, which primarily activates only the innate immune system. This approach enabled us to explore effects of myelin antigen-induced immune activation in the CNS. CNS changes were examined in the 'pre-onset' animal (days 6-12 post induction [p.i.]), when behavioral changes are seen before any $\mathrm{T}$-cell invasion, demyelination, and associated tissue damage or motor impairment (Acharjee et al., 2013).

The BLA plays an important role in anxiety, emotional arousal and modulation, and fear memory (Packard and Gabriele, 2009; Boyle, 2013; Rau et al., 2015; Fragale et al., 2016; Tran and Keele, 2016), behaviors where glutamatergic transmission plays a key role. We found enhanced glutamatergic transmission and dendritic spine density in BLA principal neurons in early EAE, changes that were associated with a "deactivated" microglial phenotype. To the best of our knowledge, this is the first demonstration of microglial "deactivation" in early inflammation in the brain that is associated with functional changes in neurons.

\section{Materials and Methods}

$E A E$ induction in mice. All animal protocols were approved by the University of Calgary Animal Care Committee. Female mice were used throughout the study as the incidence of MS in females versus males is 3:1 (Constantinescu et al., 2011). EAE was induced in 8- to 10-week-old C57BL/6N female mice (Charles River Laboratories, specified pathogen free conditions, 4/cage, on a 12:12 h light cycle) by subcutaneous immunization with $100 \mu \mathrm{g}$ myelin oligodendrocyte glycoprotein $\left(\mathrm{MOG}_{35-55}\right)$ in emulsion of a 1:1 volume with CFA (containing $4 \mathrm{mg} / \mathrm{ml}$ of heat killed Mycobacterium tuberculosis, Difco Laboratories). The mice were also injected with intravenous Bordetella pertussis toxin (200 ng; List Biological Laboratories) in $1 \times$ PBS at the time of and $2 \mathrm{~d}$ following immunization (Ousman et al., 2007). Mice injected with CFA and pertussis toxin were used as controls (referred to as CFA from here on). No anesthetics were used for this procedure. In each cohort of mice, subjects were randomly chosen for either the EAE or CFA group so that equal numbers of each group were represented. Animals were assessed for motor deficits associated with EAE as previously described (Acharjee et al., 2013) and were verified to lack the motor weakness that typically emerges only after $10-13 \mathrm{~d}$ in our hands. These animals are described as pre-onset animals in this study in which all experiments were performed in animals $6-12 \mathrm{~d}$ after EAE induction. All experiments were performed during the light phase of the cycle.

Generation of Cx3CR1-RiboTag mice. Female homozygote RiboTag mice (Sanz et al., 2009) were crossed with male CX3CR1-Cre/ERT2 mice to generate CX3CR1-RiboTag mice. This cross allows us to isolate ribosome bound translating RNA from microglia only using the TRAP technique (Heiman et al., 2008). At 3 weeks of age, the offspring received intraperitoneal injection of $1 \mathrm{mg}$ of tamoxifen, dissolved in corn oil, for 5 consecutive days. The female mice were used for EAE induction $30 \mathrm{~d}$ after the last tamoxifen injection to restrict the Cre-mediated recombination to microglia (Parkhurst et al., 2013).

Slice preparation and electrophysiology. Mice were anesthetized with isoflurane and coronal brain slices $(300 \mu \mathrm{m})$ containing the BLA were cut into a $4^{\circ} \mathrm{C}$ slicing solution $\left(5 \% \mathrm{CO}_{2} / 95 \% \mathrm{O}_{2}\right.$ saturated) containing the following (in mM): $87 \mathrm{NaCl}, 2.5 \mathrm{KCl}, 25 \mathrm{NaHCO}_{3}, 0.5 \mathrm{CaCl}_{2} \cdot 2 \mathrm{H}_{2} \mathrm{O}, 7$ $\mathrm{MgCl}_{2} \cdot 6 \mathrm{H}_{2} \mathrm{O}, 1.25 \mathrm{NaH}_{2} \mathrm{PO}_{4}, 25 \mathrm{D}$-glucose, and 75 sucrose. Slices were then transferred to a warm $\left(32^{\circ} \mathrm{C}\right)$ oxygenated recovery aCSF containing the following (in mM): $126 \mathrm{NaCl}, 2.5 \mathrm{KCl}, 26 \mathrm{NaHCO}_{3}, 2.5 \mathrm{CaCl}_{2} \cdot 2 \mathrm{H}_{2} \mathrm{O}$, $1.5 \mathrm{MgCl}_{2} \cdot 6 \mathrm{H}_{2} \mathrm{O}, 1.25 \mathrm{NaH}_{2} \mathrm{PO}_{4}$, and $10 \mathrm{D}$-glucose. Slices were maintained in oxygenated aCSF at $32^{\circ} \mathrm{C}$ for $60 \mathrm{~min}$ before being used for recording. Individual slices were placed into the recording chamber, maintained fully submerged, and continuously perfused with oxygenated $32^{\circ} \mathrm{C}$ aCSF at a flow rate of $1-2 \mathrm{ml} / \mathrm{min}$. TTX $(1 \mu \mathrm{M})$ was added to the perfusion solution to enable recording of miniature EPSCs (mEPSC) or IPSCs (mIPSCs). Picrotoxin $(100 \mu \mathrm{M})$ was also added to aCSF during mEPSC and spontaneous EPSC (sEPSC) recording. EPSCs and IPSCs were recorded using pipettes filled with Cs-gluconate internal solution (to reduce attenuation of the synaptic currents arising from the distal part of the dendrite) containing the following (in mM): $108 \mathrm{Cs}$-gluconate, 5 tetraethylammonium-Cl, $2.8 \mathrm{NaCl}, 20$ HEPES, 0.4 EGTA, 4 MgATP, $0.3 \mathrm{NaGTP}, 10$ phosphocreatine $\mathrm{Na}_{2}$, and 1 QX-314, with $\mathrm{pH}$ adjusted to 7.2 with $1 \mathrm{~m} \mathrm{CsOH}$ solution and osmolarity adjusted to 280-290 mOsmol or a K-gluconate solution of identical osmolarity containing the following (in $\mathrm{mm}$ ): $108 \mathrm{~K}$ gluconate, $8 \mathrm{Na}$ gluconate, $2 \mathrm{MgCl}_{2}, 8 \mathrm{KCl}, 1$ potassium EGTA, 4 potassium ATP, 0.3 sodium GTP, and 10 HEPES, and corrected to $\mathrm{pH} 7.2$ with $\mathrm{KOH}$. For AMPAR rectification experiments, AP-V $(50 \mu \mathrm{M})$ was added to the perfusion solution, and spermine $(0.1 \mathrm{~mm})$ was added to the Cs-Gluconate internal solution. Cells were excluded if the access resistance exceeded $20 \mathrm{M} \Omega$ or changed $>20 \%$ during the recordings. To elicit evoked currents, a stimulating electrode pipette with a resistance of $2-5 \mathrm{M} \Omega$ was filled with aCSF and was placed in the BLA to stimulate the pyramidal cell inputs. Signals were acquired at $10 \mathrm{kHz}$ and low-pass filtered at $1 \mathrm{kHz}$, collected via a Multi Clamp 700B amplifier (Molecular Devices), digitized and recorded with pClamp 9 software (Molecular Devices). eEPSC magnitude was calculated by subtraction of the peak synaptic current from prestimulation baseline in Clampfit version 9.2 (Molecular Devices). sEPSCs and mEPSCs were 
detected (and confirmed by eye) with Mini Analysis 6.0.7 software (Synaptosoft), using thresholds of 5 times RMS noise levels.

Intracerebroventricular (ICV) injections. Mice were anesthetized with isoflurane. Under stereotaxic guidance, a $23 \mathrm{Ga}$ cannula was placed dorsal to a lateral ventricle. The mice were given routine analgesic treatment and then were allowed to recover for $5 \mathrm{~d}$ after which EAE was induced and either minocycline ( $2 \mu \mathrm{g} / \mu \mathrm{l} / \mathrm{d}$; Sigma) or vehicle (sterile PBS, $1 \mu \mathrm{l} / \mathrm{d}$ ) was infused ICV (>60 s) for each of the next $6 \mathrm{~d}$. Electrophysiological recordings were performed in these mice 6-8 d after EAE induction.

Mac1-Saporin lesioning. Mac-1-saporin mouse/human toxin or saporin-IgG control $(1 \mu \mathrm{g} / 1 \mu \mathrm{l})$ (Advanced Targeting Systems, catalog \#IT-06) was injected unilaterally in the BLA under stereotaxic guidance into mice anesthetized with isoflurane. The mice were allowed to recover for $48 \mathrm{~h}$ before electrophysiological recordings were initiated. The dose of Mac-1-saporin and the time course of microglial depletion were determined by pilot experiments. After each recording session, the slices were harvested for immunofluorescence as described below. Depletion of microglia was confirmed in all experiments.

$R T$-PCR. At $7 \mathrm{~d}$ p.i. of EAE, RiboTag mice were anesthetized and the amygdala was microdissected and snap-frozen. RNA was isolated from the fresh frozen amygdala samples based on the published protocol (Sanz et al., 2009) with some modifications. Briefly, the tissue was homogenized in polysome buffer, and the supernatant from the lysate was incubated with $50 \mu \mathrm{l}$ of anti-HA magnetic beads (Miltenyi) for $2 \mathrm{~h}$ at $4^{\circ} \mathrm{C}$. Bead bound RNA was recovered by magnet, washed with high salt buffer three times, and purified using RNeasy Micro Kit (QIAGEN).

For RNA measurement in whole amygdala, 6-8 d p.i., brains from anesthetized C57BL/6N mice were harvested after perfusion with icecold PBS, microdissected on ice-cold blocks for collection of amygdalae, bilaterally and snap-frozen for RNA extraction. RNeasy-mini kit was used for RNA isolation after the tissues were homogenized in TRIzol (QIAGEN) according to the manufacturer's guidelines. For both RiboTag and nontransgenic mice, cDNA was synthesized from RNA by using a QuantiTech reverse transcription kit (QIAGEN). Semiquantitative PCR was then performed for several genes by monitoring changes in the fluorescence of a SYBR Green dye (QIAGEN) in real-time on a thermocycler (Eppendorf) (Galic et al., 2009). Primers for C1qa, C1qc, C3, and GAPDH were synthesized by Primer Assays (QIAGEN).

Golgi staining. The mice were anesthetized with sodium pentobarbital ( $80 \mathrm{mg} / \mathrm{kg}$, i.p.), perfused with PBS and the brains harvested. The Golgi silver impregnation was done according to protocol using a commercially available kit (FD Rapid GolgiStain Kit, FD NeuroTechnologies). Frozen sections $(100 \mu \mathrm{m})$ were collected, mounted and imaged using reflective confocal microscopy (Leica DM5500 B) with a $488 \mathrm{~nm}$ laser and $63 \times$ objective (1.62 NA). Six to eight BLA pyramidal neurons were imaged from at least six slices per animal $(N=3$ /group $)$ and two dendrites were analyzed per neuron; 38 dendrites were analyzed in total for each group. Both basal and apical dendrites were imaged on each neuron, and care was taken to ensure that neurons we imaged did not extend processes to the very end part of the sections to avoid dendritic stumps. Confocal image stacks were imported into Imaris TM software (Bitplane) for analysis. Images were cropped in 3D to analyze a dendrite of interest (apical or basal), the grayscale image was inverted, and the histogram adjusted to optimize the visualization. The measurement point function was used to identify the distal $20 \mu \mathrm{m}$ of the dendrite. Within this region, a protrusion was scored as a spine if it projected at least $0.5 \mu \mathrm{m}$ from the center of the shaft of the dendrite. All analyses were completed blind as to the experimental/control status of the animal.

Cytokine measurement by Luminex assay. The mice were anesthetized with sodium pentobarbital ( $80 \mathrm{mg} / \mathrm{kg}$, i.p.), and blood was collected by heart puncture into EDTA-coated tubes, followed by centrifugation at $1000 \mathrm{rpm}$ for $10 \mathrm{~min}$ at $4^{\circ} \mathrm{C}$, after which the supernatant (plasma) was collected. Mice were subsequently perfused with PBS, after which amygdalae were collected as described above and homogenized in lysate buffer containing cOmplete proteinase inhibitor tablet (Roche) for the assay. Cytokine and chemokine analyses were performed using a Millipore Mouse Cytokine Bead Panel (Eve Technologies) according to the manufacturer's protocol.
Immunofluorescence and imaging. CFA and EAE animals were anesthetized with sodium pentobarbital ( $80 \mathrm{mg} . \mathrm{kg}$, i.p.), then perfused with $4 \%$ PFA, and prepared for cryosectioning $(35 \mu \mathrm{m})$ as previously described (Acharjee et al., 2013). The sections were incubated in blocking solution (5\% donkey serum, $2 \% \mathrm{BSA}$, and $0.2 \%$ Triton-X in PBS), then incubated overnight with well-characterized primary antibodies for IBA-1 (1:1000 dilution, rabbit polyclonal, Wako Pure Chemical Industries, catalog \#019-19741, RRID:AB_839504), CD68 (1:500 dilution, rat, AbD Serotec, catalog \#MCA1957, RRID:AB_322219) and CD11b (1:600 dilution, rat, ATS, catalog \#AB-N05, RRID:AB_171796). Secondary immunolabeling $(2 \mathrm{~h})$ was performed with donkey anti-rabbit IgG Alexa-568 (1:500, Thermo Fisher Scientific, catalog \#A10042, RRID:AB_2534017) and donkey anti-rat IgG Alexa-488 (1:500, Thermo Fisher Scientific, catalog \#A-21208, RRID:AB_2535794). The antibody dilution solution contained 5\% donkey serum, $0.2 \%$ Triton-X, and 2\% BSA in PBS.

Sections were visualized by confocal microscopy (Leica DM5500 B), captured using LAS X software, and reprocessed and analyzed in Leica MetaMorph. To measure the intensity of CD68 immunofluorescence, all the images were thresholded to the same level. Identical laser intensity, gain, offset, pinhole, digital zoom, and postimaging adjustments were performed for experimental and control images, and all analyses were performed by an individual blinded to the treatment of the animal.

Immunoelectron microscopy. Three CFA control and three EAE animals were anesthetized with sodium pentobarbital ( $80 \mathrm{mg} / \mathrm{kg}$, i.p.) and perfused with $3.5 \%$ acrolein followed by $4 \%$ PFA. Transverse sections of the brain $(50 \mu \mathrm{m}$ thick) were cut in PBS ( $50 \mathrm{~mm}$ at $\mathrm{pH} 7.4)$ using a vibratome. Sections were washed in PBS, quenched with $0.3 \% \mathrm{H}_{2} \mathrm{O}_{2}$ in PBS for $5 \mathrm{~min}$ and then with $0.1 \% \mathrm{NaBH}_{4}$ for $30 \mathrm{~min}$ at room temperature, washed in Tris-buffered saline (TBS; $50 \mathrm{~mm}$ at $\mathrm{pH}$ 7.4) containing $0.01 \%$ Triton X100, and processed free floating for immunostaining. Briefly, sections were pre-incubated for $1 \mathrm{~h}$ at room temperature in a blocking solution of TBS containing 10\% FBS, 3\% BSA, and $0.01 \%$ Triton X100. They were incubated overnight at $4^{\circ} \mathrm{C}$ in the identical rabbit anti-IBA-1 antibody used for immunofluorescence (1:1000 in blocking solution; Wako Pure Chemical Industries, RRID:AB_839504) and rinsed in TBS. The sections were then incubated for $1.5 \mathrm{~h}$ at room temperature in goat anti-rabbit IgGs conjugated to biotin (1:200 in blocking solution; Jackson ImmunoResearch Laboratories) and for $1 \mathrm{~h}$ with $\mathrm{A}$ and $\mathrm{B}$ reagents of the ABC Vectastain system (1:100 in TBS; Vector Laboratories). The labeling was revealed using $\mathrm{DAB}(0.05 \%)$ and $\mathrm{H}_{2} \mathrm{O}_{2}(0.015 \%)$ in TBS for $5 \mathrm{~min}$. Afterward, the sections were postfixed flat in $1 \%$ osmium tetroxide and dehydrated in ascending concentrations of ethanol. They were treated with propylene oxide and then impregnated in Durcupan resin (EMS) overnight at room temperature. After mounting between ACLAR embedding films (EMS), they were cured at $55^{\circ} \mathrm{C}$ for $72 \mathrm{~h}$. Areas of interest (BLA region) were excised from the embedding films and glued on resin blocks. Pictures of the BLA were randomly taken at $9300 \times$, corresponding to a total surface of $\sim 4500 \mu \mathrm{m}^{2}$ captured per animal, using a FEI Tecnai Spirit G2 microscope equipped with an ORCA-HR digital camera (10 MP; Hamamatsu). Cellular profiles were identified according to previously defined criteria. In addition to their IBA-1 staining, microglial processes displayed irregular contours with obtuse angles, an electron-dense cytoplasm, numerous large vesicles, occasional multivesicular bodies, phagocytic inclusions, distinctive long stretches of endoplasmic reticulum, and were typically surrounded by pockets of extracellular space.

For quantitative analysis, each captured IBA-1-positive microglial process was traced with the Freehand Selections tool in ImageJ. The mean gray value, area, perimeter, and solidity were measured using the Shape Descriptors option (Schneider et al., 2012). Mean gray value is defined is the sum of the gray values of all the pixels in the selection divided by the number of pixels. A value of 0 corresponds to black and a value of 255 to white with an 8-bit image. Consequently, an increase in the gray value corresponds to a decrease in the electron density of the staining. Membrane ruffling, or solidity is calculated by dividing the area of an object by its convex area. The convex area is determined by ImageJ by tracing an imaginary polygon with only convex angles around the microglial process. The more ramified is the object, the bigger is the convex area, thus yielding a smaller solidity (Zanier et al., 2015). 
Direct contacts with synaptic clefts and "phagocytic" inclusions were compiled. The phagocytic inclusions were comprised of vacuoles and endosomes, sometimes containing cellular materials, such as membranes, axon terminals recognized by their $40 \mathrm{~nm}$ synaptic vesicles, and dendritic spines with a postsynaptic density (Tremblay et al., 2010b). Phagocytic inclusions containing cellular materials are referred to as "cellular inclusions." Microglia-associated extracellular space pockets containing cellular materials were designated as "extracellular digestion" and counted on a per process basis. All the ultrastructural analysis was conducted by an individual blinded to the treatment of the animals.

Statistical analysis. Data are reported as mean \pm SEM. Statistical significance was set at $p<0.05$. Following verification of a normal distribution using GraphPad 5.0, Student's unpaired $t$ test was used to compare parametric data from two groups. " $n$ " represents the number of neurons or microglial processes used in each group, and is followed by " $N$ " representing the number of mice per group. The details of the statistical analyses are provided in Results. All relevant data are available from the authors.

\section{Results}

\section{AMPA-mediated spontaneous and mEPSC frequency is} increased in EAE without change in the probability of release The principal neurons of the BLA were morphologically identified by their large pyramidal-like cell bodies. When recorded with standard internal solution, all the cells displaying this morphological feature showed varying degrees of spike adaptation. They fired 3-7 times to a depolarizing current step of $500 \mathrm{~ms}$ length, which is an electrophysiological characteristic of BLA principal neurons (Sah et al., 2003). Thus, we were confident of recording from the pyramidal cells, even in experiments where cesiumbased internal solution was used and we could not verify the spike frequency or waveform to a depolarizing current step. Standard cesium-based internal solution was used for recording AMPARmediated sEPSCs at $-70 \mathrm{mV}$ in the presence of the $\mathrm{GABA}_{\mathrm{A}^{-}}$ receptor inhibitor, picrotoxin. The frequency of sEPSCs was significantly increased in the pre-onset stage (days $6-8$ p.i.) of EAE $(\mathrm{CFA}=2.7 \pm 0.45 \mathrm{~Hz}, n=11$ cells, $N=7$ animals; EAE $=$ $4.3 \pm 0.56 \mathrm{~Hz}, n=10, N=7$; unpaired $t$ test: $t=2.287, \mathrm{df}=19$, $p=0.03 ; 3$ cohorts of animals), without any change in amplitude (CFA $=16.5 \pm 0.82 \mathrm{pA}, n=11$ cells, $N=7$ animals; $\mathrm{EAE}=$ $17.7 \pm 1.65 \mathrm{pA}, n=10, N=7$; unpaired $t$ test: $t=0.617, \mathrm{df}=19$, $p=0.509$; Fig. $1 A-C)$. However, when we used a potassiumbased internal solution, the frequency and amplitude of sEPSCs were not different in pre-onset $\mathrm{EAE}$ and CFA animals (frequency: $\mathrm{CFA}=3.3 \pm 0.86 \mathrm{~Hz}, n=6$ cells, $N=6$ animals; $\mathrm{EAE}=3.2 \pm$ $0.40 \mathrm{~Hz} ; n=8, N=7$; unpaired $t$ test: $t=0.0753, \mathrm{df}=12, \mathrm{df}=$ $19, p=0.94$ and amplitude: $\mathrm{CFA}=19.5 \pm 2.34 \mathrm{pA} ; n=6$ cells, $N=6$ animals; $\mathrm{EAE}=18.9 \pm 1.62 \mathrm{pA}, n=8, N=7$; unpaired $t$ test: $t=0.2369, \mathrm{df}=12, p=0.81 ; 2$ cohorts of animals; Fig. $1 D-F)$. Cesium reduces filtering of the synaptic currents arising from distal parts of the dendrite by blocking the potassium current, and changes in EPSC frequency seen only with cesium internal suggested that most of the changes were contributed by inputs to more distal dendrites.

To determine whether the change in frequency between CFA and EAE was caused by alteration of unitary synaptic properties, we recorded mEPSCs after bath applying the sodium channel blocker, TTX. The amplitudes of mEPSCs reflect the number and conductance of subsynaptic AMPARs, whereas the frequency reflects the probability of vesicle release $(p)$ and/or the number of synapses (Kerchner and Nicoll, 2008). We found that mEPSC frequency was significantly increased $(\mathrm{CFA}=1.02 \pm 0.15 \mathrm{~Hz}$, $n=14, N=6$; $\mathrm{EAE}=1.79 \pm 0.21 \mathrm{~Hz}, n=11, N=5$; unpaired two-tailed $t$ test: $t=2.959, \mathrm{df}=23, p=0.007,2$ cohorts of animals) without change in the amplitude (CFA $=17.3 \pm 1.03$ $\mathrm{pA}, n=14, N=6$; $\mathrm{EAE}=17.2 \pm 0.451 \mathrm{pA}, n=11, N=5$; unpaired two-tailed $t$ test: $t=0.072, \mathrm{df}=23, p=0.94$; Fig. $1 G-I$ ), indicating there was either an increase in $p$ or in the number of synapses in EAE mice. To test whether there was an alteration in $p$, we evoked EPSCs by stimulating the presynaptic inputs at the BLA with two brief pulses at an interval of $50 \mathrm{~ms}$. Paired-pulse ratio was not altered $(\mathrm{CFA}=1.08 \pm 0.04 ; n=22, N=7$; EAE: $1.13 \pm 0.06, n=17, N=5$; unpaired $t$ test: $t=0.5482, \mathrm{df}=37$, $p=0.58,2$ cohorts of animals) between the two groups (Fig. $1 \mathrm{~J}, K)$, suggesting there was no change in the probability of release; thus, the change in frequency most likely reflected increased number of synapses.

We also measured the GABA-mediated mIPSCs recorded at 0 $\mathrm{mV}$ by using cesium-based internal solution and TTX in the aCSF. We found no change in the mIPSC amplitude (CFA $=$ $29.9 \pm 0.6 \mathrm{pA}, n=7, N=3 ; \mathrm{EAE}=28.3 \pm 0.898 \mathrm{pA}, n=7, N=$ 4, unpaired two-tailed $t$ test: $t=1.525, \mathrm{df}=12, p=0.1531)$ and frequency $(\mathrm{CFA}=2.21 \pm 0.359 \mathrm{~Hz}, n=7, N=3 ; \mathrm{EAE}=2.31 \pm$ $1.29 \mathrm{~Hz}, n=7, N=4$, unpaired two-tailed $t$ test: $t=0.1568, \mathrm{df}=$ $12, p=0.8780,2$ cohorts of animals). Paired-pulse ratio was also not altered (CFA: $1.01 \pm 0.116 ; n=6, N=3$; EAE: $1.34 \pm 0.308$, $n=6, N=3$; unpaired two-tailed $t$ test: $t=1.004, \mathrm{df}=10, p=$ $0.33,2$ cohorts of animals) between the two groups, suggesting there was no change in the probability of release.

\section{Spine density is increased in EAE and associated with mature spine morphology and increase in AMPA-NMDA ratio and AMPAR subunit}

An increased number of synapses could result from more dendritic spines and/or unsilencing of silent synapses. In a silent synapse, an EPSC is absent because of a postsynaptic complement exclusively of NMDA receptors; hence, in the absence of depolarization, it cannot conduct current in response to presynaptic glutamate release. In response to sufficient depolarization, AMPARs can be inserted in the postsynaptic density, thereby making the synapse active or "unsilenced." To this end, we measured the maximum amplitude of the eEPSC at $-70 \mathrm{mV}$ (AMPAR-mediated) and then at $40 \mathrm{mV}$, at a $50 \mathrm{~ms}$ latency (NMDA-mediated), both in the presence of picrotoxin (Fig. 2A). We found that ratio of AMPA/NMDA eEPSC amplitude was increased in $\mathrm{EAE}(\mathrm{CFA}=3.3 \pm 0.41, n=15, N=7 ; \mathrm{EAE}=6.0 \pm$ $1.15 ; n=13, N=4$; unpaired two-tailed $t$ test: $t=2.335, \mathrm{df}=26$, $p=0.02 ; 2$ cohorts of animals; Fig. $2 B$ ). This relative increase in AMPARs suggests increased numbers of functional synapses in response to EAE induction.

To reconcile an increase in synapse number and AMPA signaling with decreased fear memory as reported previously (Acharjee et al., 2013), we investigated whether AMPAR dynamics played an important role in memory erasure. Synaptic removal of calcium-permeable AMPARs in the lateral amygdala is thought to be important for erasure of fear memory (Clem and Huganir, 2010), as we observed earlier. AMPARs are composed of various combinations of four subunits (GluA1-4). AMPARs lacking GluA2 have a high relative $\mathrm{Ca}^{2+}$ permeability, whereas those containing GluA2 have low $\mathrm{Ca}^{2+}$ permeability. Increased GluA2lacking AMPARs are expressed in response to inflammation (Stellwagen and Malenka, 2006; Riazi et al., 2015). When GluA2lacking subunits are present and in the presence of intracellular spermine, the $I-V$ curve exhibits inward rectification due to block by intracellular polyamines at depolarized potentials. Thus, we asked whether the GluA2-lacking AMPAR subunit composition was increased in EAE. To isolate AMPA-mediated eEPSCs, picro- 
A
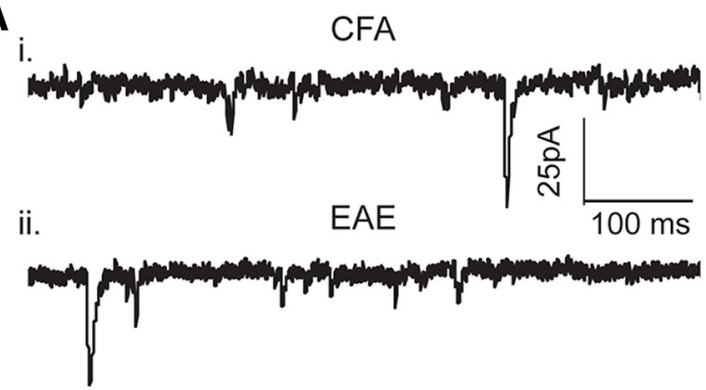

D

i.

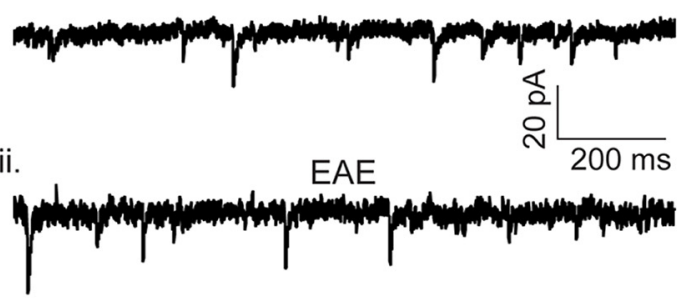

G

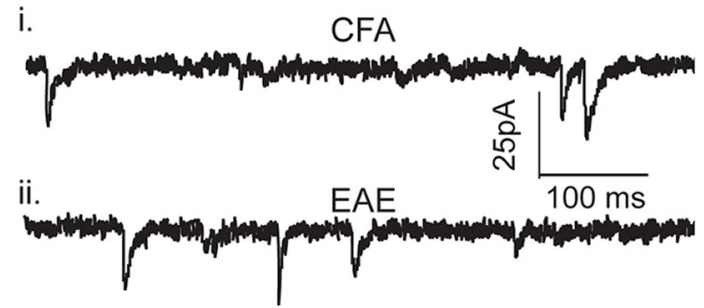

B

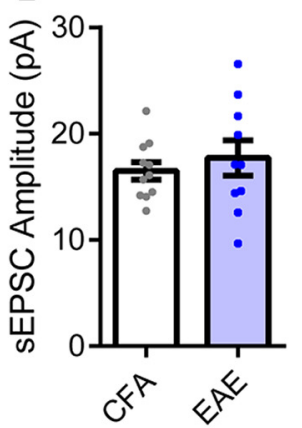

E

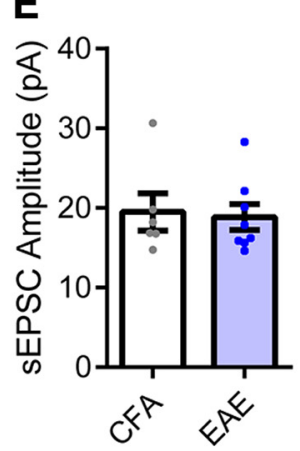

H

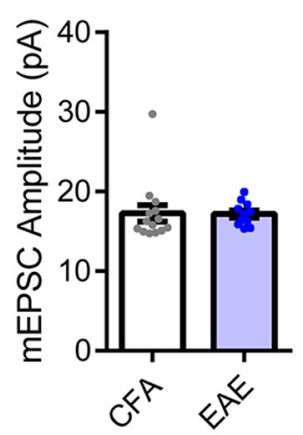

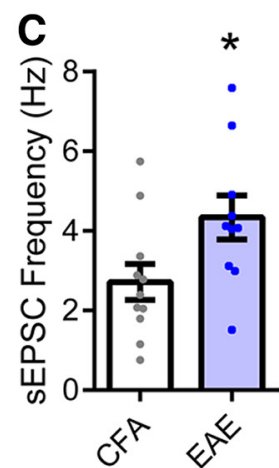

$F$

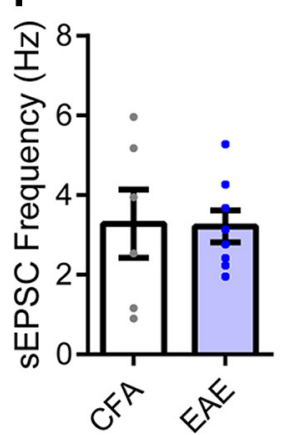

I

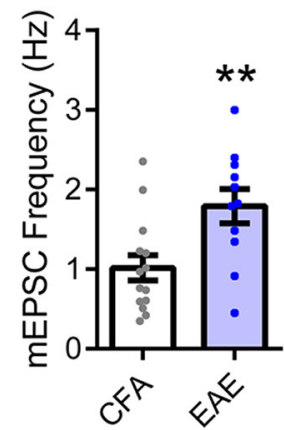

J

ii. $E A E$

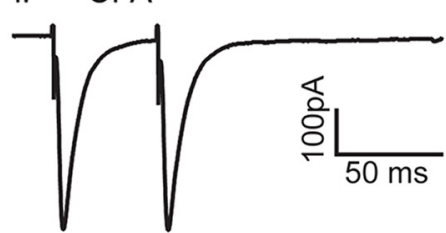

i..

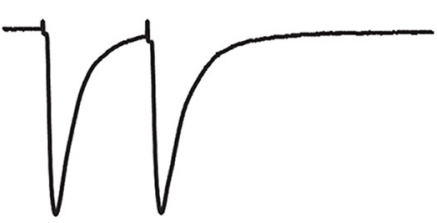

K

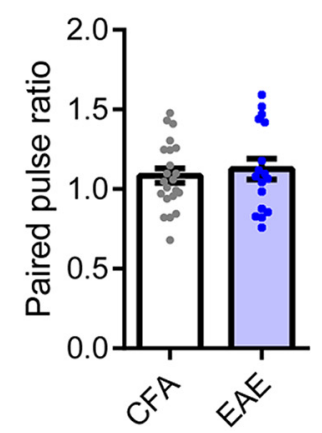

Figure 1. SEPSC and mEPSC frequency is increased in BLA pyramidal neurons in EAE. $A$, Sample voltage-clamp sEPSC recordings using a cesium-based internal solution from CFA ( $A \boldsymbol{i})$ and EAE mice (Aii). $\boldsymbol{B}, \boldsymbol{C}$, Bar graph representing sEPSC amplitude $(\boldsymbol{B})$ and frequency $(\boldsymbol{C})(n=11$ cells, $N=7$ animals for CFA; $n=10, N=7$ for EAE). D, Sample voltage-clamp sEPSC recordings with potassium gluconate-based internal solution from (FA (Di) and EAE (Dii) animals. Bar graph showing that the amplitude $(\boldsymbol{E})$ and frequency $(\boldsymbol{F})$ of sEPSCS are similar in CFA and EAE with potassium gluconate-based internal solution (CFA: $n=6$ cells, $N=6$ animals; EAE: $n=8, N=7$ ). G, Sample voltage-clamp mEPSC recordings from (FA (Gi) and EAE (Gii) animals also recorded with a cesium-based internal solution. $\boldsymbol{H}, \boldsymbol{I}$, Bar graph representing mEPSC amplitude $(\boldsymbol{H})$ and frequency $(\boldsymbol{I})(n=14, N=6$; for CFA; $n=11, N=5$ for EAE). $J$, Representative traces showing a pair of EPSCS (average of $40-60$ traces) evoked at an interstimulus interval of $50 \mathrm{~ms}$ from a CFA (Ji) and EAE (Jii) animal. $\boldsymbol{K}$, Bar graph representing the paired-pulse ratio when the two EPSCs were stimulated at an interval of $50 \mathrm{~ms}$ (CFA: $n=22, N=7$; EAE: $n=17, N=5, p=0.58$ ). Error bars indicate mean \pm SEM. ${ }^{*} p<0.05$ (unpaired Student's $t$ test). ${ }^{* *} p<0.01$ (unpaired Student's $t$ test).

toxin $(100 \mu \mathrm{m})$ and APV $(50 \mu \mathrm{m})$ were added to the bath, and spermine $(0.1 \mathrm{mM})$ was included in the internal solution. Synaptic currents were evoked by electrical stimulation of presynaptic fibers in the BLA at the rate of $0.2 \mathrm{~Hz}$ while the membrane po- tential was held at $-60 \mathrm{mV}$ and changed in $20 \mathrm{mV}$ steps between -60 and $60 \mathrm{mV}$ (Fig. 2C,D). For each holding potential, 10 EPSCs were averaged. The amplitude of eEPSCs was calculated and normalized to the amplitude of eEPSC at $-60 \mathrm{mV}$ and plot- 


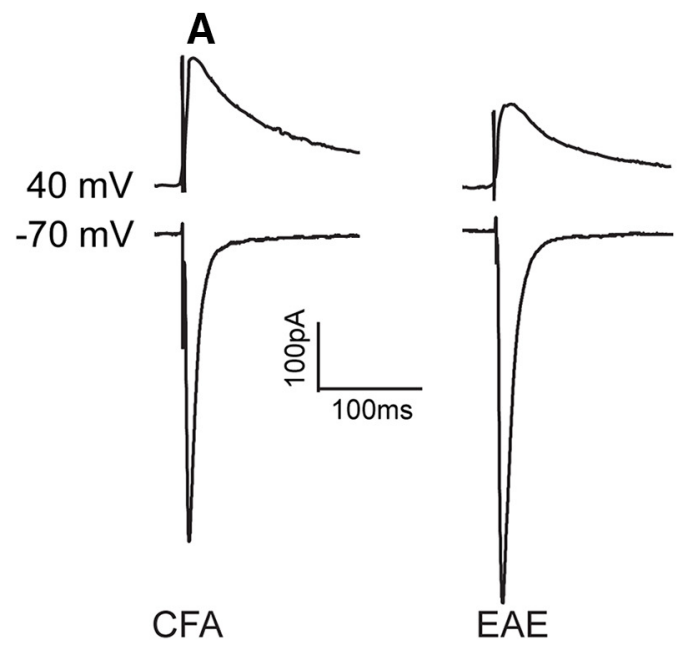

C

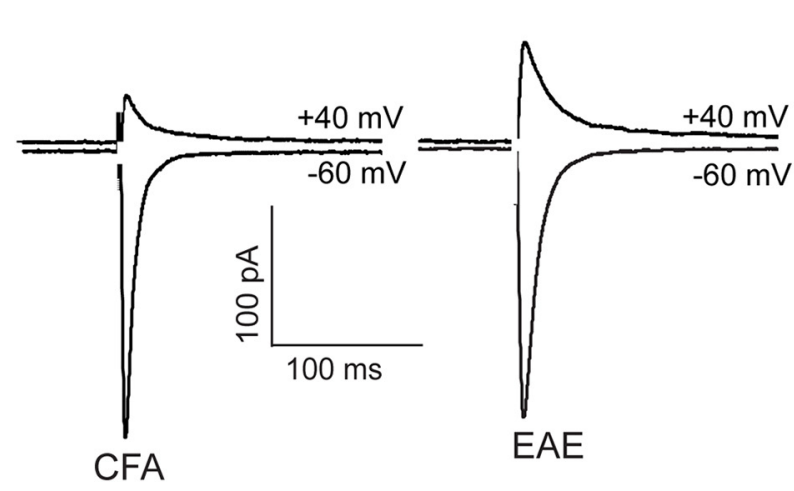

B

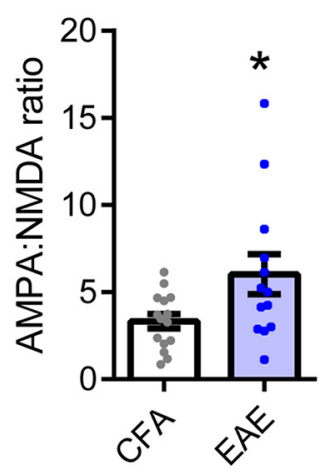

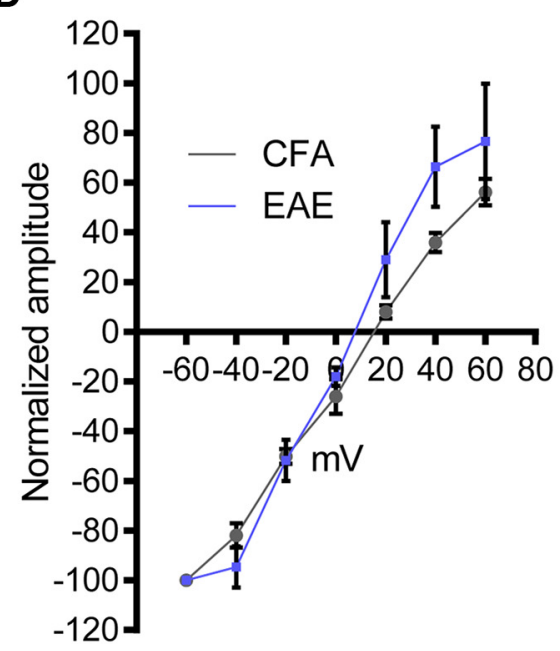

E

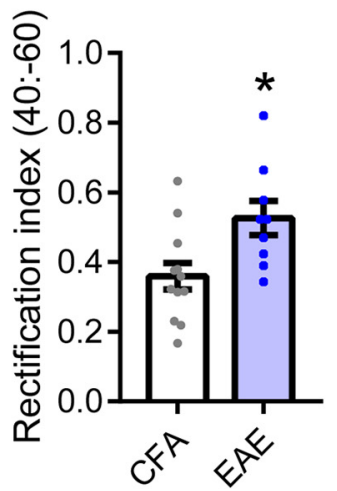

Figure 2. AMPA-NMDA ratio is increased and AMPAR dynamics are altered in EAE. A, Representative traces of evoked AMPA currents recorded at $-70 \mathrm{mV}$ and NMDA currents at $40 \mathrm{mV}$. $\boldsymbol{B}$, Bar graph represents that AMPA-NMDA ratio is increased in EAE (CFA: $n=15, N=7 ; \mathrm{EAE}: n=13, N=4 ; p=0.02$ ). C, Representative traces of AMPA currents at -60 and $40 \mathrm{mV}$ in EAE. D, Current voltage plot for AMPA EPSCS shows that AMPA is outwardly rectified. $E$, Mean rectification index, measured by the ratio of the AMPA currents at $40 \mathrm{mV}$ and $-60 \mathrm{mV}$, is significantly increased in EAE animals $(p=0.013) .{ }^{*} p<0.05$ (unpaired Student's $t$ test).

ted in an $I-V$ curve (Fig. $2 D, E$ ). The rectification index, defined as the ratio of AMPA amplitude at $40 \mathrm{mV}$ to that at $-60 \mathrm{mV}$, was increased in EAE (Fig. $2 E$; CFA: $0.35 \pm 0.04, n=11, N=5$; EAE: $0.54 \pm 0.0618$, unpaired two-tailed $t$ test: $t=0.2 .717, \mathrm{df}=19, p=$ $0.01, n=8, N=5$ ), implying that there was a higher proportion of GluA2-containing AMPAR in the synapses.

To confirm whether dendritic spine density was increased, Golgi staining was performed and BLA pyramidal neurons were identified by their characteristic pyramidal-shaped cell body (Fig. $3 A-D)$. Because our sEPSC data suggested that most of the changes could be attributed to the distal end of the dendrites, the numbers of spines across a $20 \mu \mathrm{m}$ length from the distal end of the dendrites of the pyramidal neurons were counted. One or two dendritic processes per neuron were analyzed ( 2 or 3 neurons/ animal and 2 dendrites/neuron, and 3 animals per group). Spine number was found to be increased in EAE compared with CFA control (38 dendrites/ group, CFA:17.42 \pm 0.6496 , EAE: $21.37 \pm$ 0.9604; unpaired two-tailed $t$ test: $t=3.405, \mathrm{df}=74, p=0.001$; Fig. $3 E$ ). In addition, we also examined spine morphology because changes in spine morphology are believed to represent one mechanism by which synaptic activity leaves its imprint on neu- rons. This was concurrent with an increase in spines with welldefined heads, which is correlated with spine maturation $(38$ dendrites/group, CFA: $9.395 \pm 0.6878$, EAE: $12.08 \pm 0.8694$; unpaired two-tailed $t$ test: $t=2.174$, df $=74$; Fig. 3F, $p=0.01$ ). Bifurcated spines, which are often associated with increased synaptic efficacy (Rusakov et al., 1996), were higher in number in the EAE amygdala (38 dendrites/group, CFA: $1.605 \pm 0.2573$, EAE: $2.342 \pm 0.2272$; unpaired two-tailed $t$ test: $t=2.174, \mathrm{df}=74 ; p=$ 0.03; Fig. $3 G$ ). In conclusion, an increased prevalence of spines, both bifurcated and with heads, was observed in EAE, which is in accord with an increased AMPA-NMDA ratio and a more mature/functional structure.

\section{Expression profile of cytokines in the plasma and the amygdala of EAE animals}

Proinflammatory cytokines, such as TNF- $\alpha$, secreted during inflammation, have been shown to alter synaptic plasticity (Stellwagen et al., 2005; Stellwagen and Malenka, 2006). To explore their involvement in amygdala changes, we measured cytokine levels from both plasma and amygdala of CFA $(N=5)$ and EAE $(N=5)$ animals at $\mathrm{d} 7$ p.i. by Luminex assay. Plasma cytokine 

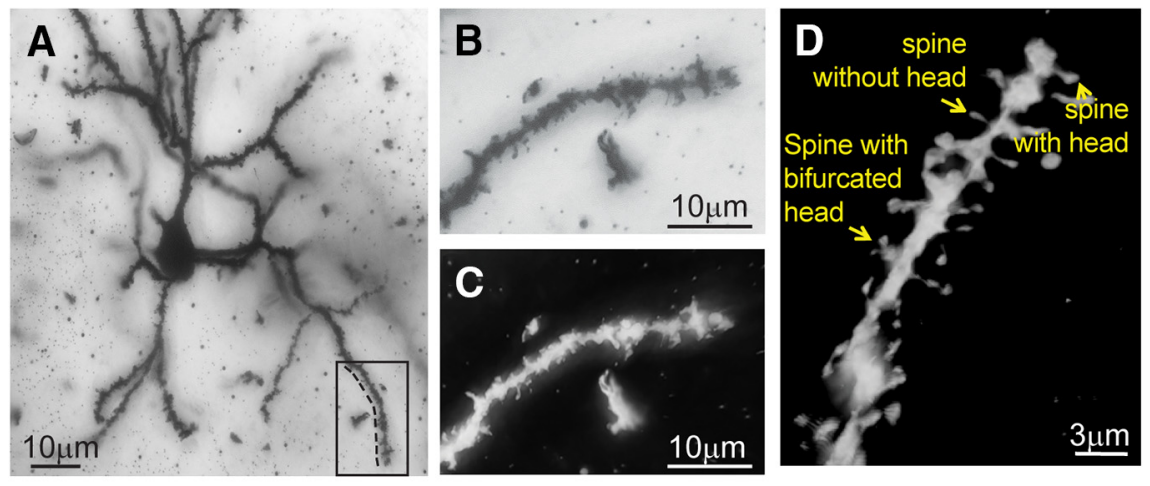

E

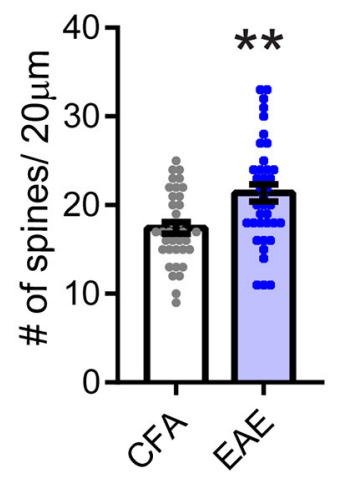

F

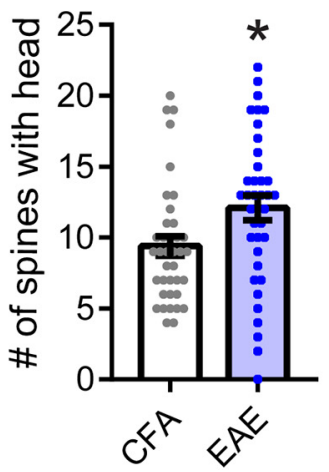

G

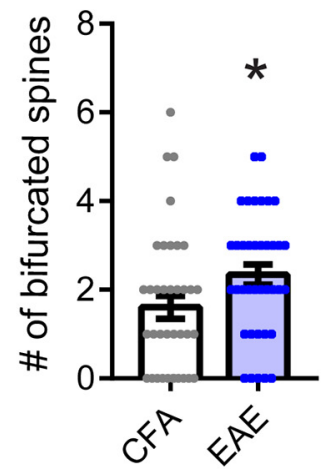

Figure 3. Dendritic spine density is increased in EAE. $A$, Representative image of a pyramidal neuron from BLA impregnated with Golgi solution. $B$, Zoomed image of the area under box in $A$, which is the distal $20 \mu \mathrm{m}$ of the dendrite. $C, D, 3 D$ reconstruction of the image in $\boldsymbol{D}$, which enabled us to visualize the spine in 3 dimensions. $\boldsymbol{D}$, Spines with head and birfurcation. $\boldsymbol{E}-\boldsymbol{G}$, Each dot indicates the number of spines in each dendrite. Number of dendrites analyzed in each group $=38 ; N=3$ animals in each group. $\boldsymbol{E}-\boldsymbol{G}$, Graphical representation of number of $\operatorname{spines}(\boldsymbol{E}, p=0.001)$, spines with head $(\boldsymbol{F}, p=0.01)$, and bifurcated spines $(\boldsymbol{G}, p=$ 0.03 ), all of which were increased in EAE. Error bars indicate mean \pm SEM. ${ }^{*} p<0.05$ (unpaired Student's $t$ test). ${ }^{* *} p<0.01$ (unpaired Student's $t$ test).

analysis revealed that IL-17, CXCL10 (IP-10), CXCL1 (KC), and MIP- $1 \alpha$ were significantly upregulated in pre-onset EAE (Table 1 ). All of these cytokines play a role in autoimmunity (Wildner and Kaufmann, 2013; Kuwabara et al., 2017). In contrast to the elevations seen in the plasma of EAE mice, cytokine levels in the amygdala were similar between CFA and EAE groups (Table 2), indicating a dissociation of peripheral and amygdalar cytokine levels.

\section{Microglia show "deactivated" morphology in EAE}

Given the role of microglia in regulating synapse number (Tremblay et al., 2011; Stephan et al., 2012; Schafer et al., 2013; Wu et al., 2013, 2015), we explored a possible role for microglia in the BLA during early EAE. Microglial morphology reflects their functional activation state (Zanier et al., 2015). In the unchallenged state, surveillant microglia present a ramified morphology, highly motile processes that interact with synapses, whereas upon "activation," their processes typically retract as the cell body becomes hypertrophied (Tremblay et al., 2010a). "Activated" microglia are also well known to display an increased expression of IBA-1 in various contexts of injury and disease (Norden et al., 2016; Wang et al., 2017). We have previously shown that electron microscopy (EM) can reveal the functional state of microglia in a highly sensitive manner (Tremblay et al., 2010a). Based on that work, we quantified microglial ultrastructural features in preonset EAE by transmission EM using an immunoperoxidase staining against IBA-1 (Fig. 4A,B). The electron density of the

immunoperoxidase precipitate was significantly reduced in EAE, which was quantified by calculating the mean gray value ( $N=4$ /group, 3-4 ROI/ animal, CFA: $107.4 \pm 0.8086$ a.u., $n=415$, EAE: $114.3 \pm 0.9053$ a.u., $n=315$ sections; $p<$ 0.0001; Fig. 4C). We looked at processes in ultrathin sections, which revealed an increased area (CFA: $0.3009 \pm 0.02635$ $\mu \mathrm{m}^{2}, n=415$ sections, EAE: $0.3828 \pm$ $0.03 \mu \mathrm{m}^{2}, n=315$ sections; unpaired two-tailed $t$ test: $t=2.05, \mathrm{df}=728, p=$ 0.04; Fig. 4D) and especially an increased perimeter (CFA: $2.649 \pm 0.1015 \mu \mathrm{m}, n=$ 415 sections; EAE: $3.213 \pm 0.1462 \mu \mathrm{m}$, $n=315$ sections, unpaired two-tailed $t$ test: $t=3.268$, df $=728, p=0.001$; Fig. $4 E$ ), indicating more complex morphology of the ramifications. Microglial processes were also found to display a reduced solidity (CFA: $0.7791 \pm 0.00728$, $n=415$ sections; EAE: $0.7497 \pm 0.0095$ a.u., $n=315$ sections; unpaired twotailed $t$ test: $t=2.511, \mathrm{df}=728, p=0.01$ ), a measure of plasma membrane ruffling associated with motility (Ridley, 1994), thus suggesting an increased surveillance behavior (Fig. $4 F$ ). It may be noted that IBA-1 stains both microglia and macrophages, so we cannot rule out that some cells may be macrophages invading the brain from the periphery. Decreased IBA-1 staining, more complex ramifications, and increased plasma membrane ruffling in EAE are overall indicative of a ramified state in which microglial surveillance is preserved.

\section{Microglia showed less extracellular digestion}

Microglial processes constantly survey the brain parenchyma, transiently contact neuronal elements, and can also engulf cellular debris and eliminate synapses. Using immunocytochemical EM against IBA-1, we found direct contacts between microglial process and neuronal perikarya, as well as presynaptic elements, postsynaptic elements, and synaptic clefts (Fig. $5 A, D, E$ ). Synaptic elements showing signs of autophagy were also frequently contacted by microglia in both CFA and EAE (Fig. 5C-E). Microglial inclusions, sometimes containing recognizable synaptic elements that probably resulted from phagocytosis, were occasionally encountered in both conditions (Fig. $5 F$ ). In addition, features associated with extracellular digestion or "exophagy" (Haka et al., 2016), such as microglial processes in association with extracellular space pockets that contained partially to completely disrupted cellular membranes, as well as synaptic elements (Fig. 5A-E, asterisks), were observed. These features are suggestive of ongoing extracellular digestion, either mediated by microglial remodeling of the extracellular matrix or release of lysosomal proteins. The prevalence of extracellular digestion was significantly reduced in EAE ( $N=3$ /group, 68-152 processes/ animal, CFA: $0.2072 \pm 0.01992, n=415$ sections; EAE: $0.08254 \pm 0.01553, n=315$ sections; unpaired two-tailed $t$ test: $t=4.639, \mathrm{df}=728, p<0.001$; Fig. $5 J$ ). Accordingly, the expression of CD68 in IBA-1-labeled cells, a lysosome-associated pro- 
Table 1. Cytokines levels in plasma of mice under different experimental conditions (Luminex assay) ${ }^{a}$

\begin{tabular}{|c|c|c|c|}
\hline & CFA (pg/ml) & EAE (pg/ml) & $\begin{array}{l}\text { Significance } \\
\text { (unpaired Student's } t \text { test) }\end{array}$ \\
\hline Eotaxin & $490.8 \pm 26.3$ & $335.2 \pm 63.5$ & $p=0.05$ \\
\hline G-CSF & $9152.9 \pm 2331.5$ & $7517.1 \pm 1122.5$ & $p=0.54$ \\
\hline GM-CSF & $16.7 \pm 5.1$ & $30.3 \pm 11.3$ & $p=0.07$ \\
\hline IFNy & $65.3 \pm 23.1$ & $119.6 \pm 52.6$ & $p=0.37$ \\
\hline IL-1 $1 \alpha$ & $85.7 \pm 20.7$ & $90.9 \pm 16.3$ & $p=0.84$ \\
\hline IL-1 $\beta$ & $8.9 \pm 1.3$ & $13.7 \pm 2.6$ & $p=0.14$ \\
\hline IL-2 & $3.3 \pm 1.4$ & $47.2 \pm 27.6$ & $p=0.15$ \\
\hline IL-3 & $1.1 \pm 0.7$ & $4.7 \pm 1.7$ & $p=0.86$ \\
\hline IL-4 & $0.2 \pm 0.1$ & $1.2 \pm 0.8$ & $p=0.21$ \\
\hline IL-5 & $10.9 \pm 3.2$ & $27.8 \pm 6.6$ & $p=0.04^{*}$ \\
\hline IL-6 & $173.6 \pm 59.4$ & $274.4 \pm 36.0$ & $p=0.18$ \\
\hline IL-7 & $6.5 \pm 1.6$ & $4.1 \pm 0.6$ & $p=0.19$ \\
\hline IL-9 & ND & ND & - \\
\hline IL-10 & $3.7 \pm 0.9$ & $8.5 \pm 2.9$ & $p=0.10$ \\
\hline IL-12 (p40) & $8.4 \pm 2.4$ & $10.3 \pm 1.8$ & $p=0.46$ \\
\hline IL-12 (p70) & $8.8 \pm 5.0$ & $43.4 \pm 31.1$ & $p=0.37$ \\
\hline IL-13 & $78.4 \pm 9.4$ & $110.3 \pm 17.4$ & $p=0.14$ \\
\hline IL-15 & $48.1 \pm 29.9$ & $27.6 \pm 8.6$ & $p=0.95$ \\
\hline |L-17 & $18.9 \pm 4.8$ & $38.4 \pm 2.6$ & $p=0.007^{* *}$ \\
\hline IP-10 & $362.4 \pm 47.1$ & $511.6 \pm 241.3$ & $p=0.56$ \\
\hline KC & $128.1 \pm 30.2$ & $290.5 \pm 46.7$ & $p=0.01^{* *}$ \\
\hline LIF & $1.4 \pm 0.3$ & $1.3 \pm 0.2$ & $p=0.97$ \\
\hline LIX & $389.2 \pm 83.6$ & $423.6 \pm 82.8$ & $p=0.81$ \\
\hline MCP-1 & $42.7 \pm 11.0$ & $82.4 \pm 18.7$ & $p=0.10$ \\
\hline M-CSF & $16.6 \pm 2.1$ & $19.1 \pm 3.3$ & $p=0.54$ \\
\hline MIG & $490.2 \pm 53.8$ & $503.6 \pm 211.8$ & $p=0.66$ \\
\hline MIP-1 $\alpha$ & $109.1 \pm 17.0$ & $208.1 \pm 23.9$ & $p=0.009^{* *}$ \\
\hline MIP-1 $\beta$ & $96.5 \pm 12.4$ & $145.2 \pm 25.1$ & $p=0.12$ \\
\hline MIP-2 & $6.8 \pm 0.6$ & $11.7 \pm 2.5$ & $p=0.09$ \\
\hline RANTES & $27.8 \pm 2.4$ & $31.5 \pm 4.9$ & $p=0.51$ \\
\hline TNF- $\alpha$ & $11.3 \pm 3.9$ & $16.6 \pm 4.4$ & $p=0.39$ \\
\hline VEGF & ND & ND & - \\
\hline
\end{tabular}

${ }^{a}$ Five animals were used in each group. ND, Nondetectable.

${ }^{*} p<0.05 ;{ }^{* *} p<0.01$.

tein often used as a marker of microglial "activation" or "phagocytosis" was significantly reduced in the BLA of EAE mice compared with CFA controls (CFA: $12.5 \pm 0.129$, EAE: $12.1 \pm$ $0.116 ; N=4$ /group, 2-3 ROIs per animal; unpaired two-tailed $t$ test: $t=2.619$, df $=18, p=0.01$; Fig. $6 A, B)$.

\section{Involvement of the complement system}

Increased numbers of dendritic spines, along with altered microglial activity, raise the intriguing possibility that synaptic pruning is reduced in EAE. The complement system has been shown to tag particular synapses for elimination (Schafer et al., 2012; Stephan et al., 2012), leading us to ask whether an underlying molecular mechanism could be the alteration of complement protein expression in the amygdala of EAE animals. To this end, we measured RNA levels of C1qa, C1qc, and C3 in the amygdala and found that $\mathrm{C} 3$ levels were downregulated in EAE versus CFA animals (CFA: $1.169 \pm 0.0 .0456$, EAE: $0.8044 \pm 0.0704, N=4$ or 5 , unpaired two-tailed $t$ test: $t=4.078, \mathrm{df}=7 ; p=0.004$; Fig. $7 A$ ). To test whether this C3 downregulation was mediated by microglia, we isolated microglial RNA from the amygdala of the CX3CR1 Cre/Ribo-Tag transgenic mouse line and found no change in the expression levels of $\mathrm{Clqa}, \mathrm{Clqc}$, and $\mathrm{C} 3$ in the EAE amygdala microglia, compared with CFA amygdala microglia. (Fig. 7B).
Table 2. Cytokine levels in amygdala of mice under different experimental conditions (Luminex assay) ${ }^{a}$

\begin{tabular}{|c|c|c|c|}
\hline & $\begin{array}{l}\text { CFA (pg/600 mg } \\
\text { tissue) }\end{array}$ & $\begin{array}{l}\mathrm{EAE}(\mathrm{pg} / 600 \mathrm{mg} \\
\text { tissue) }\end{array}$ & $\begin{array}{l}\text { Significance } \\
\text { (unpaired } \\
\text { Student's } t \text { test) }\end{array}$ \\
\hline Eotaxin & $19.9 \pm 1.6$ & $19.8 \pm 0.3$ & $p=0.34$ \\
\hline $\mathrm{G}-\mathrm{CSF}$ & $9.9 \pm 2.4$ & $6.3 \pm 1.9$ & $p=0.26$ \\
\hline GM-CSF & $20.7 \pm 4.9$ & $23.6 \pm 2.5$ & $p=0.59$ \\
\hline IFNy & ND & ND & - \\
\hline IL-1 $\alpha$ & $65.0 \pm 9.4$ & $47.2 \pm 20.2$ & $p=0.44$ \\
\hline IL-1 $\beta$ & $48.7 \pm 3.7$ & $39.4 \pm 4.0$ & $p=0.12$ \\
\hline IL-2 & $175.5 \pm 14.2$ & $145.0 \pm 10.4$ & $p=0.12$ \\
\hline IL-3 & ND & ND & - \\
\hline IL-4 & $2.0 \pm 0.3$ & $5.6 \pm 4.0$ & $p=0.39$ \\
\hline IL-5 & $0.2 \pm 0.1$ & $0.2 \pm 0.0$ & $p=0.83$ \\
\hline IL-6 & $1.8 \pm 0.4$ & $1.5 \pm 0.2$ & $p=0.58$ \\
\hline IL-7 & $5.3 \pm 1.1$ & $4.9 \pm 1.2$ & $p=0.77$ \\
\hline IL-9 & $73.1 \pm 3.5$ & $74.1 \pm 8.7$ & $p=0.92$ \\
\hline IL-10 & $11.4 \pm 2.2$ & $5.7 \pm 0.9$ & $p=0.04^{*}$ \\
\hline IL-12 (p40) & $0.8 \pm 0.1$ & $0.3 \pm 0.1$ & $p=0.07$ \\
\hline IL-12 (p70) & $2.4 \pm 0.3$ & $2.4 \pm 0.4$ & $p=0.98$ \\
\hline IL-13 & $15.6 \pm 3.3$ & $12.9 \pm 2.4$ & $p=0.52$ \\
\hline IL-15 & $45.1 \pm 6.6$ & $36.1 \pm 2.1$ & $p=0.22$ \\
\hline IL-17 & $5.2 \pm 1.0$ & $3.4 \pm 0.7$ & $p=0.17$ \\
\hline IP-10 & $70.9 \pm 44.1$ & $39.1 \pm 9.6$ & $p=0.57$ \\
\hline $\mathrm{KC}$ & $20.9 \pm 1.9$ & $14.9 \pm 2.5$ & $p=0.09$ \\
\hline LIF & $1.2 \pm 0.1$ & $1.0 \pm 0.2$ & $p=0.22$ \\
\hline LIX & ND & ND & - \\
\hline MCP-1 & $20.8 \pm 5.3$ & $21.2 \pm 1.8$ & $p=0.94$ \\
\hline M-CSF & $4.0 \pm 0.3$ & $3.3 \pm 0.3$ & $p=0.13$ \\
\hline MIG & $11.6 \pm 2.5$ & $10.3 \pm 3.2$ & $p=0.74$ \\
\hline MIP-1 $\alpha$ & $9.8 \pm 1.6$ & $7.7 \pm 0.6$ & $p=0.25$ \\
\hline MIP-1 $\beta$ & ND & ND & - \\
\hline MIP-2 & $27.3 \pm 3.4$ & $24.9 \pm 6.6$ & $p=0.76$ \\
\hline RANTES & $2.9 \pm 0.6$ & $3.7 \pm 0.4$ & $p=0.29$ \\
\hline TNF- $\alpha$ & $2.1 \pm 0.5$ & $3.4 \pm 0.5$ & $p=0.11$ \\
\hline VEGF & ND & ND & - \\
\hline
\end{tabular}

${ }^{a}$ Five animals were used in each group. ND, Nondetectable.

${ }^{*} p<0.05$.

Deactivating/eliminating microglia increases the spontaneous EPSC frequency in EAE

Given that microglia play a critical role in synaptic pruning, we hypothesized that inhibiting microglial activation by minocycline administration in EAE could further alter the synaptic phenotype observed in EAE. Thus, we applied minocycline by ICV injections in EAE animals to specifically affect the CNS and bypass the peripheral immune effects. We measured mEPSC amplitude and frequency at $-70 \mathrm{mV}$ after $\sim 20-24 \mathrm{~h}$ of minocycline treatment. We found that minocycline increased mEPSC frequency (EAE-PBS: $2.0 \pm 0.33 \mathrm{~Hz}, n=6, N=4$; EAE-minocycline: $3.1 \pm 0.31 \mathrm{~Hz} ; n=10, N=5$, unpaired two-tailed $t$ test: $t=$ $2.353, \mathrm{df}=14 ; p=0.03)$, but not amplitude in EAE mice compared with EAE-vehicle-treated mice (EAE-PBS: $14.7 \pm 1.36 \mathrm{pA}$, $n=6, N=4$; EAE-minocycline: $14.7 \pm 0.859 \mathrm{pA} ; n=10, N=5$, unpaired two-tailed $t$ test: $t=0.06211, \mathrm{df}=14 ; p=0.03$; Fig. $8 A-C)$. Thus, the EAE phenotype is even more apparent after additional microglial inactivation. However, we acknowledge that minocycline, in addition to impairing microglial proinflammatory and phagocytic activity, has many other unrelated effects; however, our use of ICV injection at least eliminated the peripheral effects of minocycline (Brundula et al., 2002; Giuliani et al., 2005).

Thus, to determine further whether microglia specifically control synaptic transmission in the BLA, we injected Saporin 

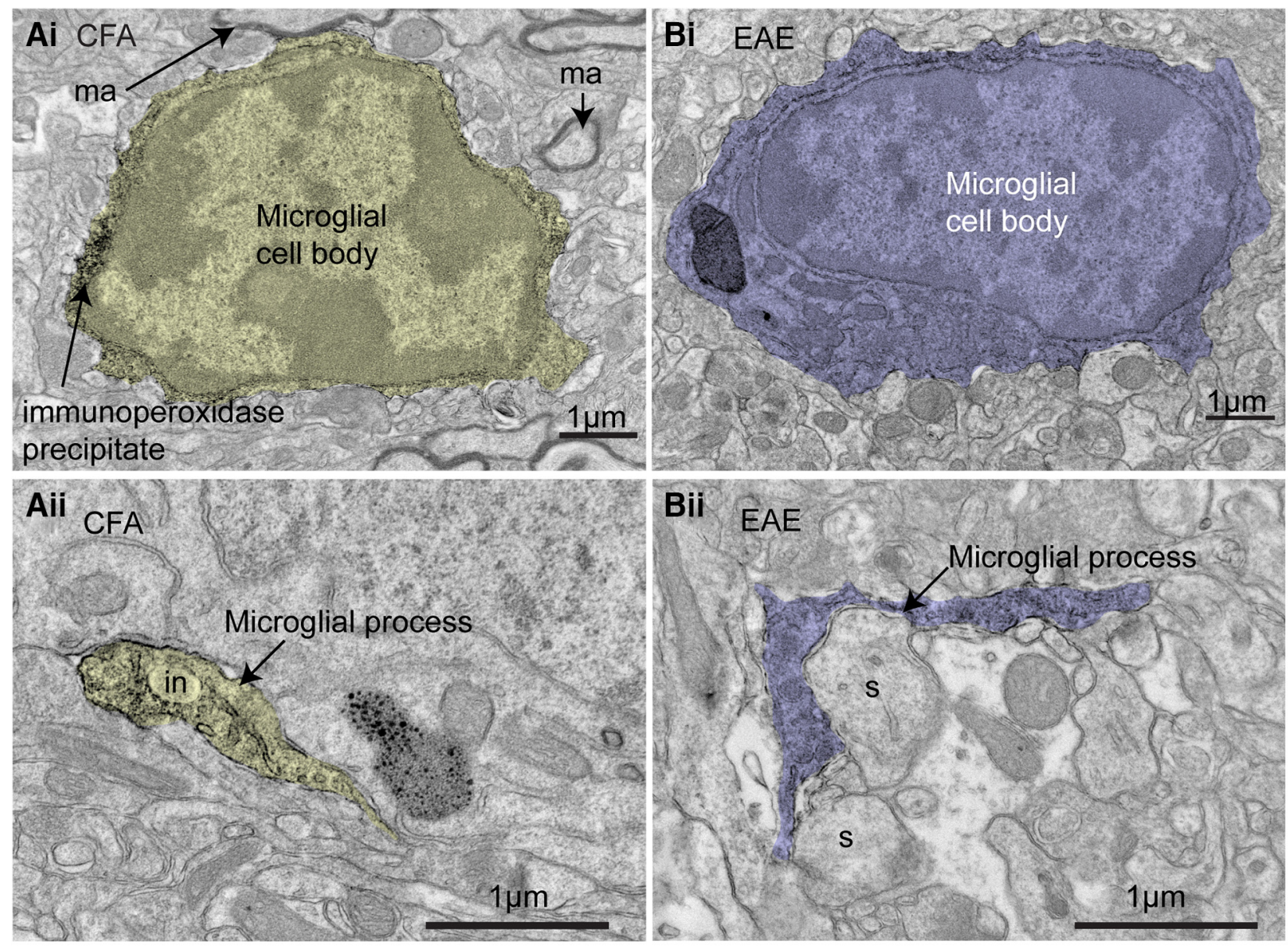

\section{Mean Grey value}

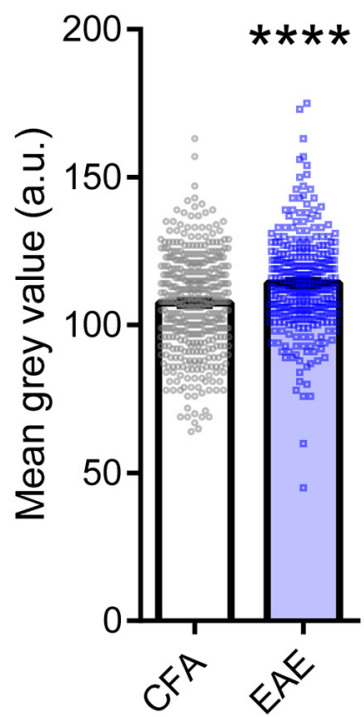

Area

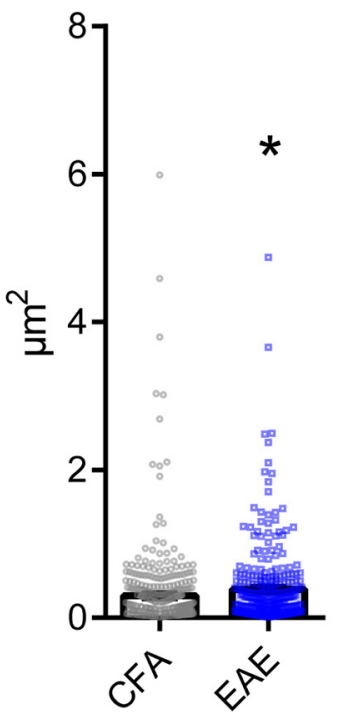

$\mathbf{E}$

Perimeter

$\mathbf{F}$

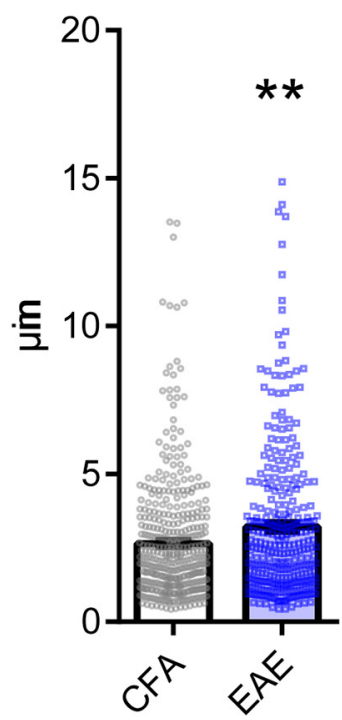

Solidity

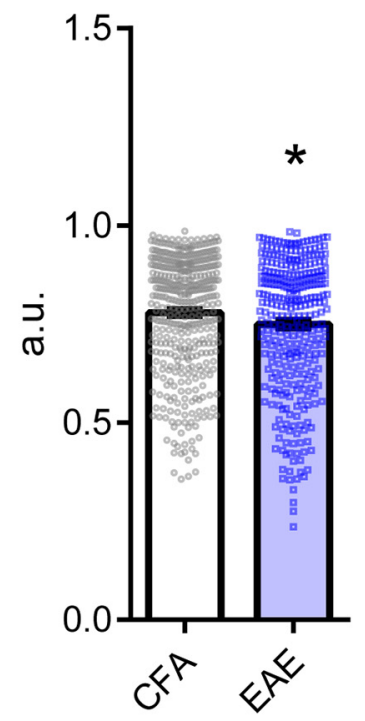

Figure 4. Changes in microglial ultrastructure observed in the amygdala upon EAE. A, B, Examples of microglial cell bodies (Ai, Bi) and processes (Aii, Bii), both colored for clarity, showing the difference in IBA-1-staining intensity measured between $C F A(\boldsymbol{A})$ and EAE $(\boldsymbol{B})$ animals. in, Cellular inclusion; ma, myelinated axon; $\mathrm{s}$, dendritic spine. $\boldsymbol{C}$, The immunoperoxidase precipitate was significantly reduced in electron density in EAE, resulting in an increase of mean gray value $(p<0.0001) . \boldsymbol{D}-\boldsymbol{F}$, Analysis of the EM images showed that microglial processes increased the complexity of their ramifications in $E A E$, as revealed by their increased area $(p=0.04)$, and especially perimeter $(p=0.001)(E)$, and displayed a reduced solidity, a measure of plasma membrane ruffling associated with motility, which is calculated by dividing the measured area by convex area $(p=0.01)(\boldsymbol{F})$. Graphs represent average \pm SEM on a per microglial process basis (3 animals/group; (FA: $N=3$, processes analyzed $=415 ; \mathrm{EAE}: N=3$, processes analyzed $=315$ ). Error bars indicate mean \pm SEM. ${ }^{*} p<0.05$ (unpaired Student's $t$ test). ${ }^{* *} p<0.01$ (unpaired Student's $t$ test). ${ }^{* * * *} p<$ 0.001 (unpaired Student's $t$ test). 

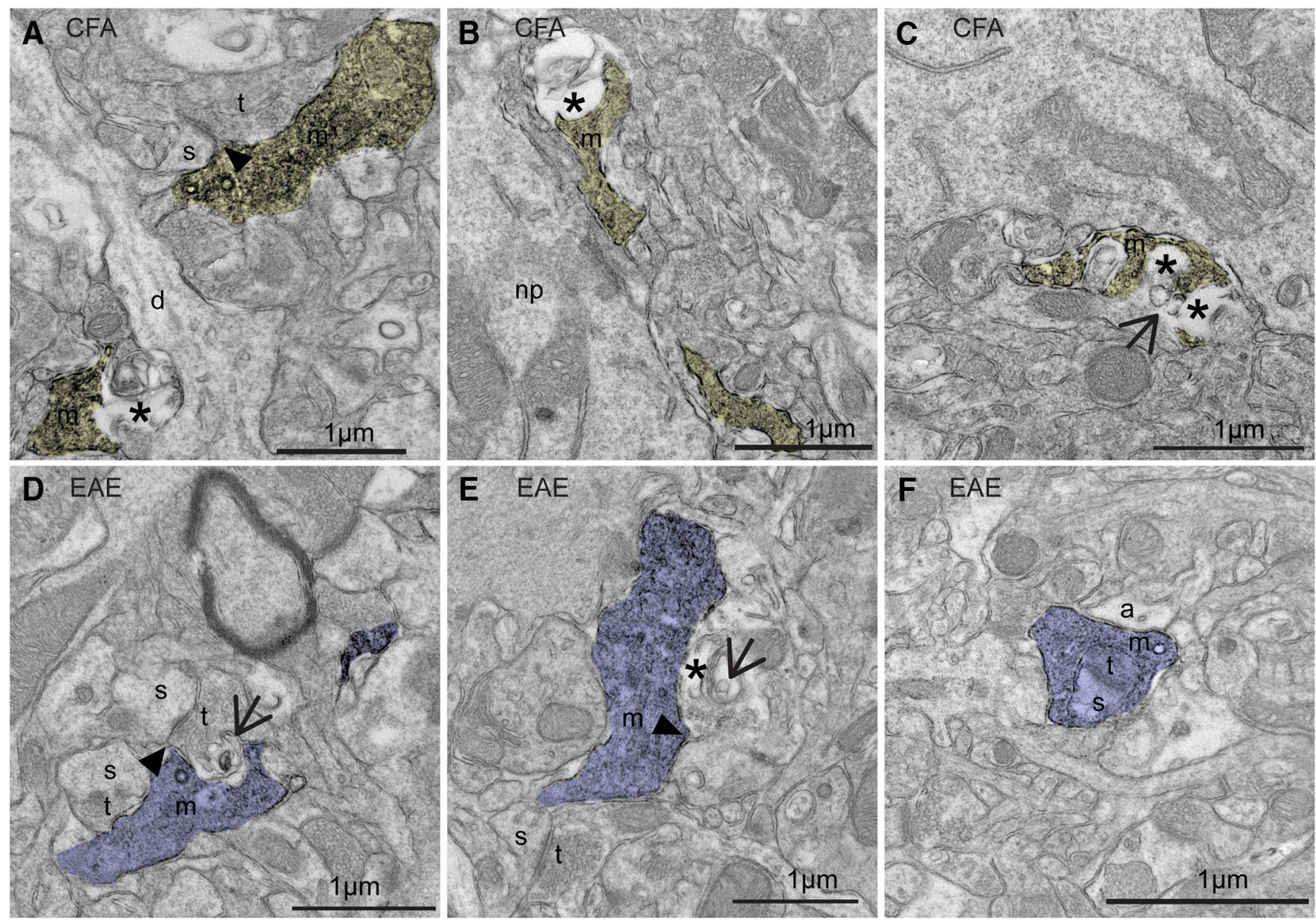

G

\section{Cleft contact}

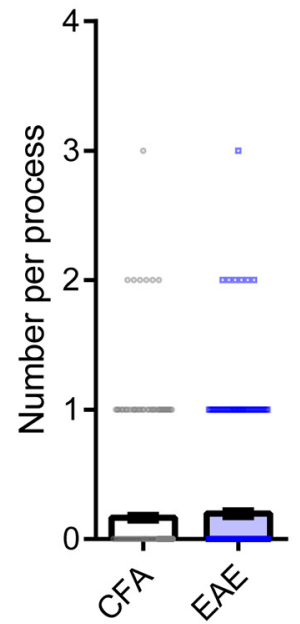

H

Phagocytic inclusion

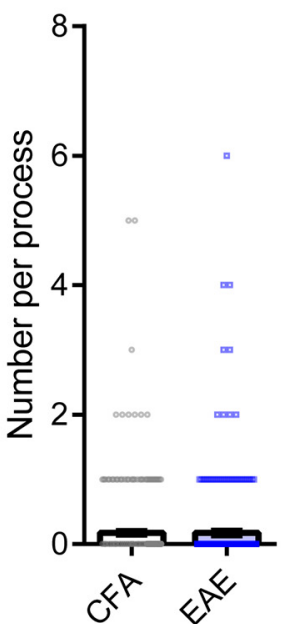

I

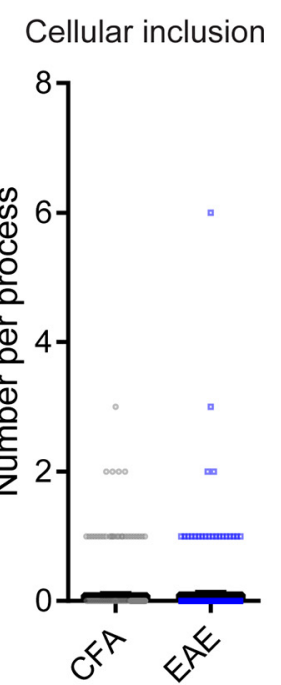

$\mathbf{J}$

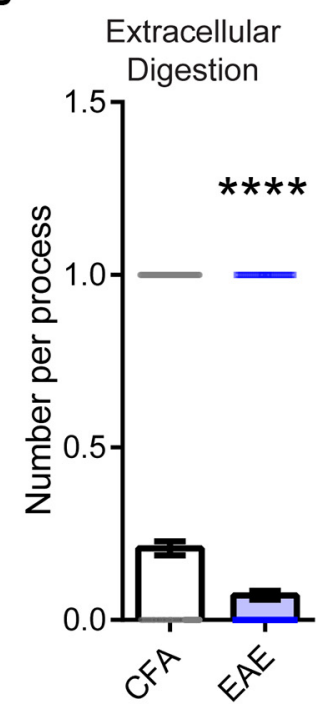

Figure 5. Microglial ultrastructure analysis reveals reduced extracellular digestion. Direct contacts between microglial processes ( $\mathrm{m}$; colored) and neuronal dendrites (d) as well as perikarya ( $\mathrm{np}$ ) were observed in (FA and EAE conditions, as displayed in $A, B$. Synaptic elements showing signs of autophagy were frequently contacted by the microglia, especially in $E A E$ ( $C-E$, arrows). Arrowheads indicate direct microglial contacts with synaptic clefts. A synapse between an axon terminal ( $t$ ) and a dendritic spine (s) that appears to be completely surrounded or internalized by a microglial process is also displayed in $\boldsymbol{F}$. In addition, microglial processes frequently associated with extracellular space pockets that contained partially to completely disrupted cellular elements $(*)$, indicating ongoing extracellular digestion. a, Astrocytic process. $\mathbf{G}-\boldsymbol{J}$, No differences in direct microglial contacts with synaptic clefts $(\boldsymbol{G})$, phagocytic inclusions $(\boldsymbol{H})$, and cellular inclusions $(\boldsymbol{I})$ are observed between CFA and EAE. J, The prevalence of extracellular digestion was by contrast reduced in EAE. Graphs represent mean \pm SEM on a per process basis ( 3 animals/group; CFA: $N=3$, processes analyzed $=415 ; \mathrm{EAE}: N=3$, processes analyzed $=419) .{ }^{* * * *} p<0.0001$ (unpaired Student's $t$ test). 
A

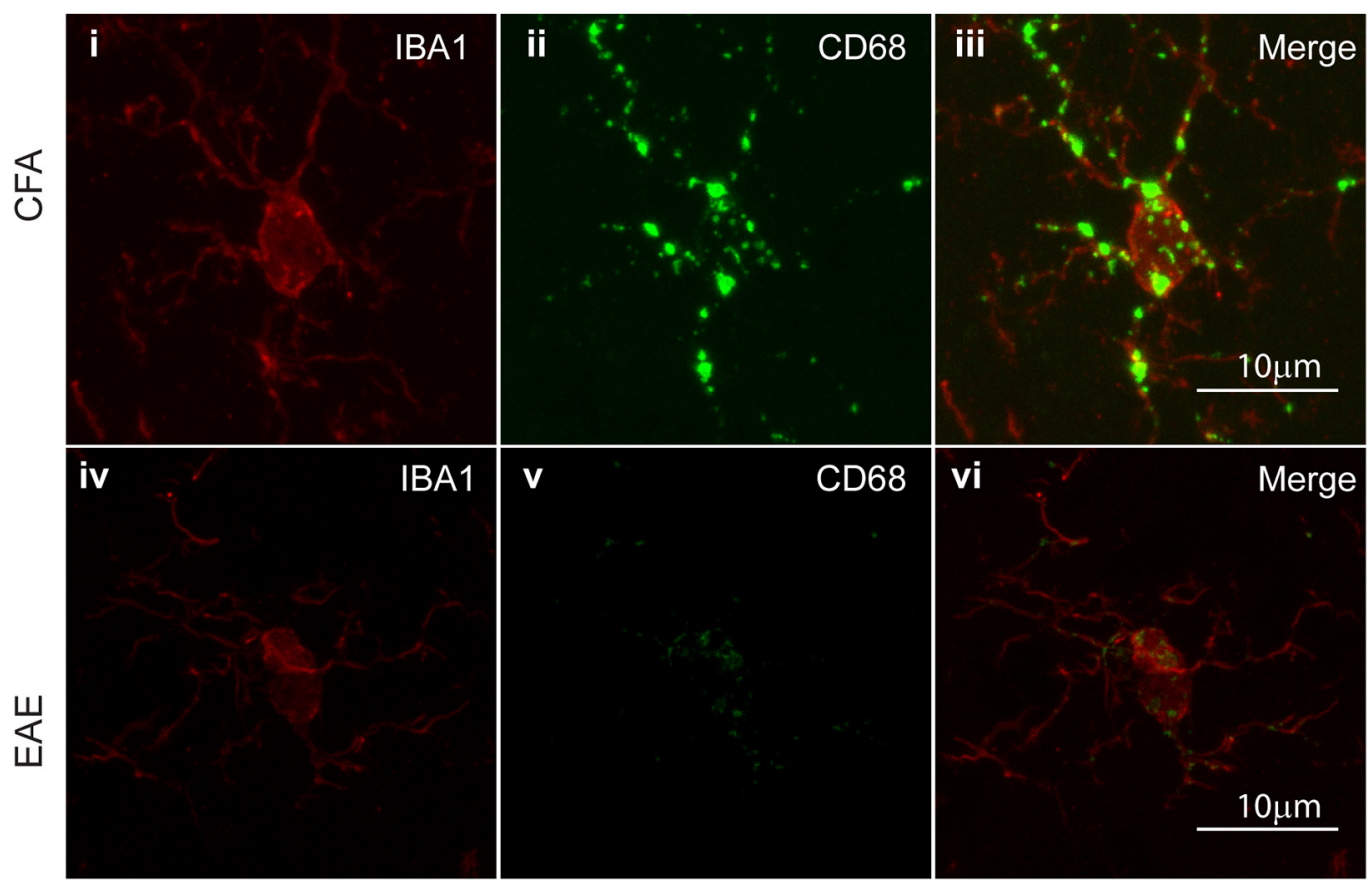

B

\section{B}

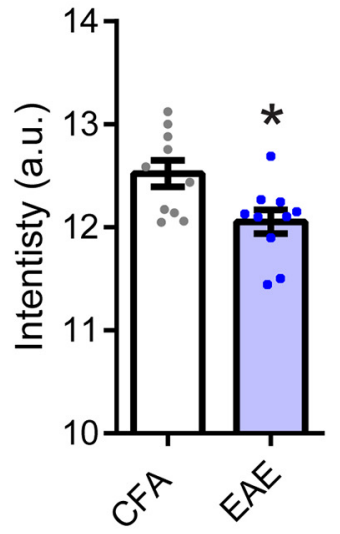

Figure 6. CD68 immunoreactivity in the microglia of EAE is reduced. A, Micrograph showing examples of IBA-1 (Ai, Aiv), CD68 (Aii, Av), and CD68+ IBA-1 merged images (Aiii, Avi) from CFA and EAE animals. B, Quantitative analysis shows that CD68 immunoreactivity is decreased in EAE (CFA: $n=10, N=5$, EAE: $n=10, N=5, p=0.01)$. ${ }^{*} p<0.05$ (unpaired Student's $t$ test).

A i

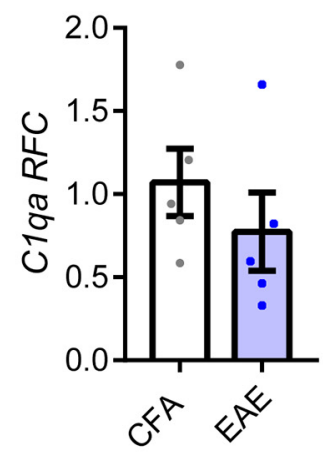

B i

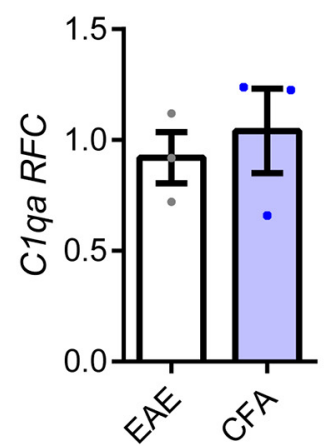

ii

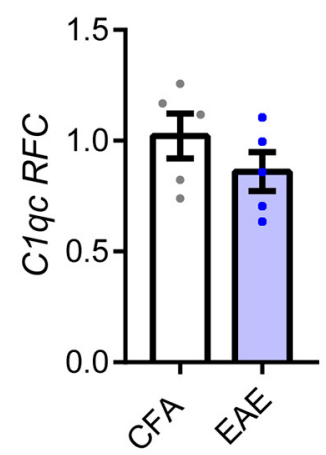

ii

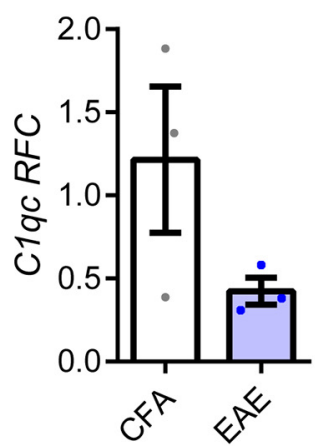

iii

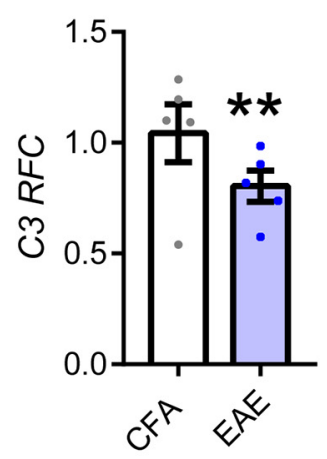

iii

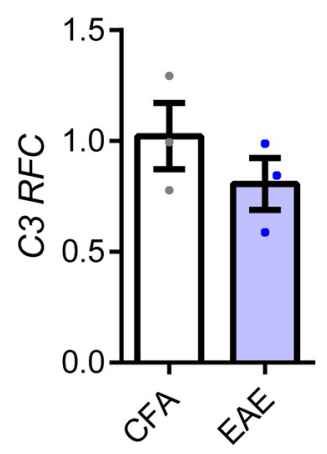

Figure 7. Complement component mRNA expression in the amygdala. $\boldsymbol{A}$, Amygdala transcript expression of $c 1 q$ a $(\boldsymbol{A} \boldsymbol{i}), \mathrm{c} 1 q \mathrm{C}$ (Aii), and 3 (Aiii) for CFA and EAE are represented graphically ( $N=4$ or 5/group). Error bars indicate mean \pm SEM. ${ }^{* *} p=0.004$ (unpaired Student's $t$ test). $\boldsymbol{B}$, Bar graph representing microglial only RNA transcript expression of $c 1 q$ a (Bi), c $1 q$ c (Bii), and C3 (Biii) from the amygdala of CFA and EAE animals ( $N=3 /$ group).

toxin conjugated to macrophage antigen complex-1 (Mac-1, integrin CD11b/ CD18 receptor localized to microglia) directly into the BLA of $\sim 8$-week-old C57BL/6N females to transiently deplete microglia. IgG-Saporin, which does not bind to any specific receptor, was used as a control. After $48 \mathrm{~h}$, the brains were harvested and sliced for whole-cell recording. Depletion of microglia in the BLA after $48 \mathrm{~h}$ was confirmed in each animal by immunofluorescent staining using CD11b antibody in the Mac1-Saporin group. As expected, we observed no intact microglia around the site of injection, with only nonspecific debris observed. Thus, there was $100 \%$ depletion of microglia in the area (Fig. $8 D$ ). We found that Mac1Saporin injection increased mEPSC frequency (Saporin: $2.3 \pm 0.38 \mathrm{~Hz}, n=7$, $N=3$; Mac1-Saporin: $3.5 \pm 0.21 \mathrm{~Hz}$; $n=9, N=4$; unpaired two-tailed $t$ test: $t=2.412, \mathrm{df}=14 ; p=0.03)$, but not amplitude (Saporin: $16 \pm 0.685 \mathrm{pA}, n=$ 7, $N=3$; Mac1-Saporin: $14.8 \pm 0.645$ pA; $n=9, N=4$; unpaired two-tailed $t$ test: $t=1.278, \mathrm{df}=14 ; p=0.22) \mathrm{com}-$ pared with Saporin-treated control mice in the BLA (Fig. $8 E-G$ ). These experiments demonstrate that both inhibiting microglial activation and transiently depleting microglia replicate the increased MEPSC frequency seen in the BLA of early EAE animals. 
A

i. $\quad$ EAE - PBS

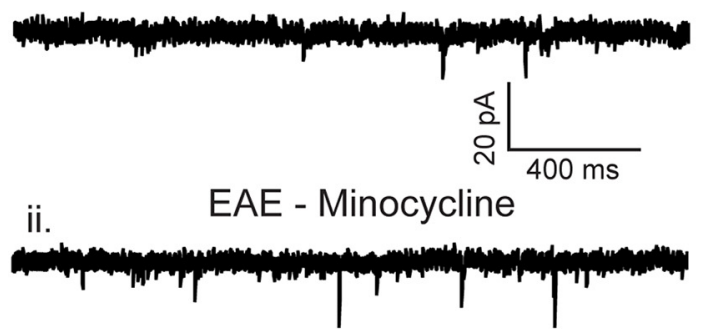

D

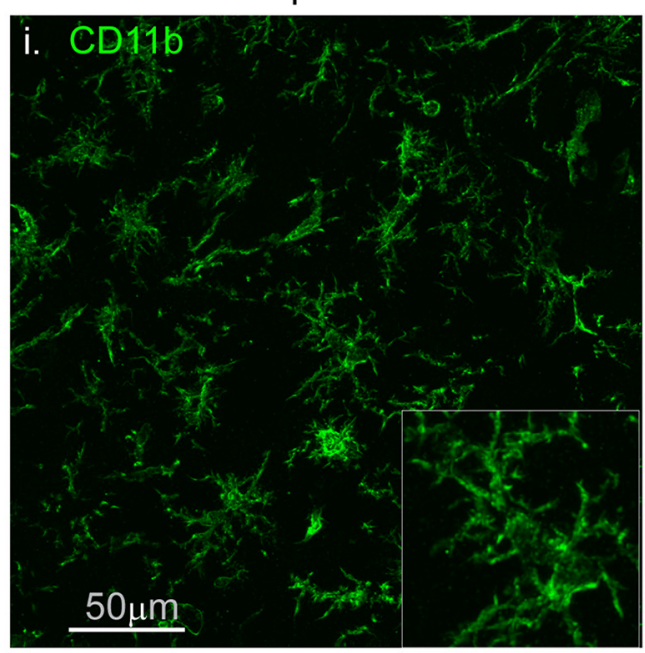

E

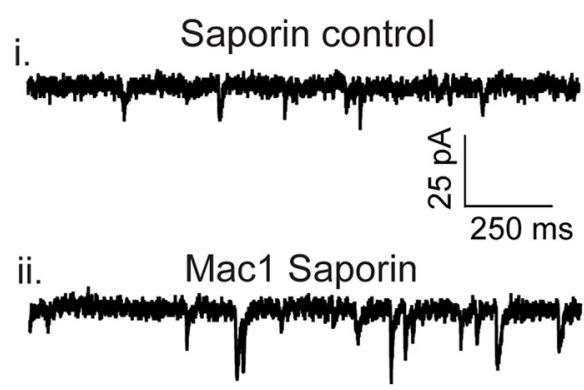

B

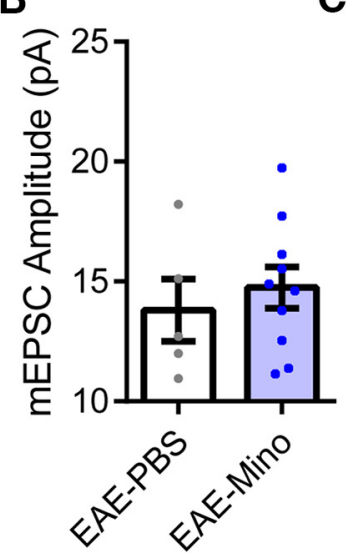

C

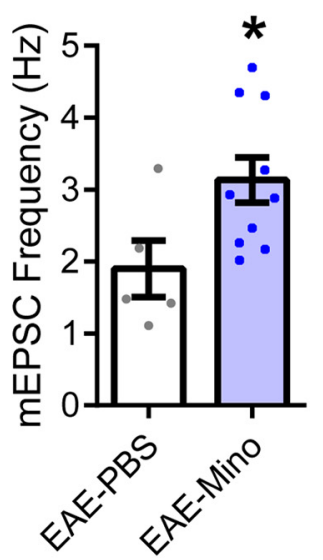

Mac1-Saporin

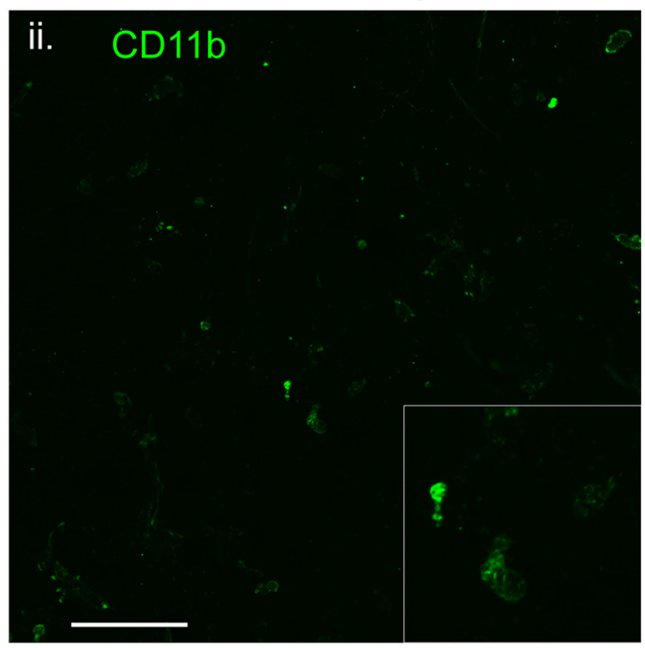

F

G
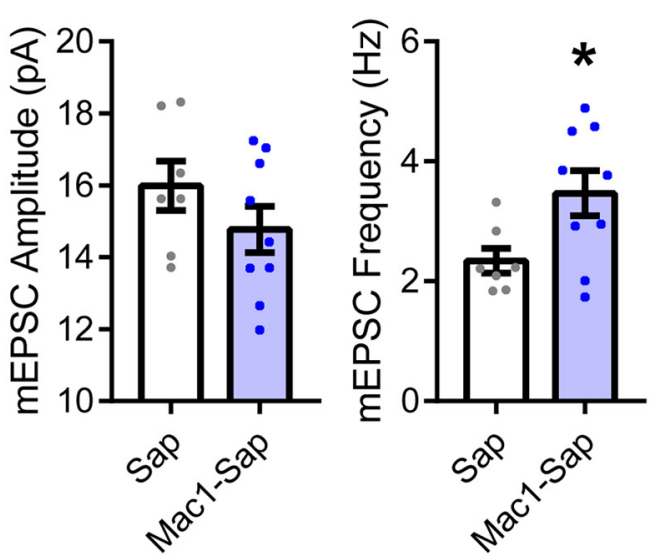

Figure 8. Daily ICV minocycline administration and microglial ablation increase mEPSC frequency without change in amplitude. $A$, Sample voltage-clamp mEPSC recordings from EAE animals receiving ICV PBS (Ai) or minocycline (Aii). B, C, Bar graph showing that there is no difference in the amplitude between EAE animals with and without ICV minocycline (EAE-PBS: $n=6, N=4$; EAE-minocycline: $n=10, N=5)(\boldsymbol{B})$, whereas the frequency is increased in EAE-minocycline animals $(p=0.03)$. $\boldsymbol{D}$, Depletion of microglia after injection of Saporin toxin conjugated to macrophage antigen complex-1 in the BLA was confirmed by immunofluorescence of CD11b antibody in the Mac1-Saporin group (Dii), and lgG-Saporin, which used as a control, did not show any ablation (Di). Insert is $2 x$ digital magnification. $\boldsymbol{E}-\boldsymbol{G}$, After $48 \mathrm{~h}$, the brains were harvested and sliced for whole-cell recording. Mac1-Saporin injection increased $\mathrm{mEPSC}$ frequency $(\boldsymbol{G})$, but not amplitude $(\boldsymbol{F})$, in C57BL/6N mice compared with Saporin-treated control mice. Error bars indicate mean \pm SEM. ${ }^{*} p<0.05$ (unpaired Student's $t$ test).

\section{Discussion}

In this study, we have investigated cellular changes associated with behavioral alterations in the very early stages of an autoimmune CNS disease, using the EAE model of MS. We previously showed that, in the early stages of EAE, before the onset of motor symptoms (Acharjee et al., 2013), mice displayed reduced spatial and fear memory, and anxiety-like behavior. We now report that early EAE is associated with increased sEPSC and mEPSC fre- 
quency, but not amplitude or changes in the paired-pulse ratio in the BLA of EAE mice. These features are concordant with an increased number of synapses, an interpretation supported by our Golgi stains where we found a greater density of dendritic spines in EAE mice. A parallel increase in the AMPA-NMDA ratio and change in AMPAR dynamics is also consistent with an increase in the number of mature functional synapses and dendritic spines in response to EAE induction (Danglot et al., 2012; Hanse et al., 2013). It is thought that new spines are associated with more AMPARs compared with NMDA receptors (Zito et al., 2009). The AMPAR activation can lead to spine maturation (Fischer et al., 2000; Hoshiko et al., 2012). A recent study showed evidence that microglia can induce spine lengthening, switching from one bouton to the other, leading most likely to the formation of multiple-synapse bouton (Weinhard et al., 2018). Our thought is that, when microglia are "less active," the nascent spines expressing AMPARs are allowed to mature without being "handled" by the microglia, thereby displaying a mature morphology, a hypothesis that warrants further investigation. We also found in EAE animals that microglia, which are involved in synaptic pruning, showed a morphologically complex ramified phenotype (through the EM analysis) with decreased expression of the activation or phagocytosis marker CD68 and decreased extracellular digestion. These data indicate that microglial activity is decreased in the amygdala, likely permitting an increase in the numbers of excitatory synapses. Additionally, as a proof of principle, we also showed that minocycline-induced microglial deactivation or transient depletion of $\mathrm{CD} 11 \mathrm{~b}^{+}$microglial cells in the brain similarly resulted in increased mEPSC frequency compared with control. Together, this resulted in enhanced BLA glutamatergic transmission, a state known to be associated with heightened affective behaviors (Shekhar et al., 2005; Padival et al., 2013; Masneuf et al., 2014; Suvrathan et al., 2014).

Glutamate receptor plasticity is measured in response to various environmental and physiological changes. For example, synaptic removal of calcium-permeable AMPARs in the lateral amygdala is thought to be important for erasure of fear memory, as we observed earlier (Clem and Huganir, 2010). Similar to our findings on glutamatergic transmission and spine density, psychological stress resulted in increased spine density and mEPSC frequency without any change in mEPSC amplitude and pairedpulse ratio (Hubert et al., 2014).

Changes in dendritic spine density have been previously described in the EAE model. A decreased number of spines was reported in the striatum at the peak of disease (d25), but this was compared with untreated controls rather than CFA-treated animals as we used (Centonze et al., 2009). In contrast, no change was observed in spine density of somatosensory cortex neurons between CFA and EAE at d7, d14, and d28 p.i. (Yang et al., 2013). We also performed spine counts in the pyramidal neurons of the hippocampus of the same animals and, in contrast to what we found in the BLA, there was no change in spine density (data not shown). As we observed an increase in BLA dendritic spine number at d7 p.i., it is apparent that different regions of the brain may exhibit different morphological reactions to the insult. Whether this is due to temporal and/or compositional differences in cytokine profile in the different areas or whether local as contrasted with global changes are responsible, is yet unknown.

Glutamatergic transmission is relevant in the context of EAE and MS. For instance, increased glutamate in the CSF and altered levels of glutamate transporters have been reported in MS pa- tients (Ohgoh et al., 2002; Bolton and Paul, 2006), but this may be entirely unrelated to the early changes we detected in EAE. In the striatum in the early stages of EAE (d7-d10 p.i.), AMPA mediated sEPSC and mEPSC frequency and decay time are also increased (Centonze et al., 2009; Haji et al., 2012), and these changes were linked to increased microglial activation, revealed by amoeboid morphology (Haji et al., 2012). In contrast, we found that ICV administration of minocycline to EAE mice or Mac1-Saporin injection in the BLA of naive mice exacerbated the synaptic phenotype we measured in EAE amygdala. This suggests that inhibition of microglial activation could be responsible for the synaptic changes we observed. A future experiment examining how Mac1Saporin or minocycline treatment affects behavior could link the synaptic phenotype, with microglia function and behavior.

Complementary to our minocycline and Mac1-Saporin data, we observed that microglia have a complex ramified morphology in the EAE group, consistent with reduced levels of activation (Hristovska and Pascual, 2015; Zanier et al., 2015). Microglia can react rapidly to infection, trauma, and other danger signals, by retracting their processes and enlarging their cell body. However, microglial phenotypes vary depending on the type of stimulus and by brain region (Morrison and Filosa, 2013; Abiega et al., 2016). Genome-wide analyses of microglia of different CNS regions showed that cerebellar and hippocampal microglia exist in a more vigilant state than do microglia in other brain areas (Grabert et al., 2016). Even within the hippocampus, the microglia of area CA3 are more sensitive to LPS compared with those of CA1 or dentate gyrus (Madore et al., 2013). Thus, it is not surprising that we saw different effects in BLA compared with what another group reported in the striatum.

In EAE, autoreactive $\mathrm{T}$ cells stimulate the myeloid cells, including resident microglia and macrophages. Microglia play a definitive role in EAE development as repression of microglial proinflammatory activity can inhibit the development of the EAE motor defects (Heppner et al., 2005). In contrast, a recent study with microglial gene profiling using microarray analysis revealed suppression of microglial genes during the early stages of EAE development; specifically, the genes related to their phagocytic functions and cytoskeleton organization were suppressed (Yamasaki et al., 2014). This suppression could have multiple effects, such as reduced phagocytosis, cytokine, chemokine, and metalloproteinase production (Shemer et al., 2015). We also found reduced extracellular digestion, reduction of IBA-1 and CD68 staining, but no change in cytokine mRNA expression (Acharjee et al., 2013) or protein cytokine levels in the amygdala at this stage, even though plasma cytokine levels were increased as expected. Additionally, the lysosome-associated protein CD68, which exclusively colocalized with IBA-1 immunoreactivity, was reduced in the EAE amygdala, consistent with reduced microglial activation. Reduced extracellular spaces between the neuron and microglia were also observed in the EAE amygdala. These spaces generally contained material undergoing digestion in the CFA controls (synaptic elements that could be identified or membranes in a more advanced state of digestion), suggesting a reduced pruning of synaptic materials in EAE (Haka et al., 2009; Singh et al., 2016). This raises the possibility that ongoing synaptic pruning is reduced in EAE, accounting for the increased spine number and the ensuing enhanced glutamatergic transmission. The complement protein $\mathrm{C} 3$, which tags the synapses to be eliminated by the microglia cells, was downregulated in the EAE mouse amygdala. In contrast, microglia isolated from CX3CR1/ Ribo-Tag mice showed no difference in C3 level, indicating that the source of $\mathrm{C} 3$ is not from microglia in the EAE mice. This is not 
surprising because the primary source of C3 in many degenerative diseases is the reactive astrocyte (Liddelow et al., 2017).

In conclusion, our evidence shows that microglia suppression in early EAE results in an increase in synapse number and leads to enhanced glutamatergic transmission due to decreased synaptic pruning by microglia. Thus, we show, for the first time, that microglial "deactivation" in the early phase of CNS autoimmune inflammation is linked to both physiological and structural changes in neurons. "Deactivation" in the context of inflammatory CNS disease contrasts with the generally accepted idea that microglial activation is the predominate response. Also, our results that show contrasts between EAE and CFA-treated animals further support a role for the acquired immune system in the regulation of microglial function (Kipnis, 2016). Additional studies need to be performed to delineate how microglial function changes over the period of EAE induction and evolution, as well as the role of extracellular digestion in maintaining spine density. Further studies of this nature will enhance our understanding of the importance of microglial control of synaptic transmission in health and disease.

\section{References}

Abiega O, Beccari S, Diaz-Aparicio I, Nadjar A, Layé S, Leyrolle Q, GómezNicola D, Domercq M, Pérez-Samartín A, Sánchez-Zafra V, Paris I, Valero J, Savage JC, Hui CW, Tremblay MÈ, Deudero JJ, Brewster AL, Anderson AE, Zaldumbide L, Galbarriatu L, et al. (2016) Neuronal hyperactivity disturbs ATP microgradients, impairs microglial motility, and reduces phagocytic receptor expression triggering apoptosis/microglial phagocytosis uncoupling. PLoS Biol 14:e1002466. CrossRef Medline

Acharjee S, Nayani N, Tsutsui M, Hill MN, Ousman SS, Pittman QJ (2013) Altered cognitive-emotional behavior in early experimental autoimmune encephalitis-cytokine and hormonal correlates. Brain Behav Immun 33: 164-172. CrossRef Medline

Bialas AR, Stevens B (2013) TGF-beta signaling regulates neuronal C1q expression and developmental synaptic refinement. Nat Neurosci 16:17731782. CrossRef Medline

Bolton C, Paul C (2006) Glutamate receptors in neuroinflammatory demyelinating disease. Mediators Inflamm 2006:93684. CrossRef Medline

Boyle LM (2013) A neuroplasticity hypothesis of chronic stress in the basolateral amygdala. Yale J Biol Med 86:117-125. Medline

Brundula V, Rewcastle NB, Metz LM, Bernard CC, Yong VW (2002) Targeting leukocyte MMPs and transmigration. Brain 125:1297-1308. CrossRef Medline

Centonze D, Muzio L, Rossi S, Cavasinni F, De Chiara V, Bergami A, Musella A, D’Amelio M, Cavallucci V, Martorana A, Bergamaschi A, Cencioni MT, Diamantini A, Butti E, Comi G, Bernardi G, Cecconi F, Battistini L, Furlan R, Martino G (2009) Inflammation triggers synaptic alteration and degeneration in experimental autoimmune encephalomyelitis. J Neurosci 29:3442-3452. CrossRef Medline

Clem RL, Huganir RL (2010) Calcium-permeable AMPA receptor dynamics mediate fear memory erasure. Science 330:1108-1112. CrossRef Medline

Constantinescu CS, Farooqi N, O’Brien K, Gran B (2011) Experimental autoimmune encephalomyelitis (EAE) as a model for multiple sclerosis (MS). Br J Pharmacol 164:1079-1106. CrossRef Medline

Danglot L, Freret T, Le Roux N, Narboux Nême N, Burgo A, Hyenne V, Roumier A, Contremoulins V, Dauphin F, Bizot JC, Vodjdani G, Gaspar P, Boulouard M, Poncer JC, Galli T, Simmler MC (2012) Vezatin is essential for dendritic spine morphogenesis and functional synaptic maturation. J Neurosci 32:9007-9022. CrossRef Medline

D’Mello C, Riazi K, Le T, Stevens KM, Wang A, McKay DM, Pittman QJ, Swain MG (2013) P-selectin-mediated monocyte-cerebral endothelium adhesive interactions link peripheral organ inflammation to sickness behaviors. J Neurosci 33:14878-14888. CrossRef Medline

Feinstein A (2011) Multiple sclerosis and depression. Mult Scler 17:12761281. CrossRef Medline

Feinstein A, Magalhaes S, Richard JF, Audet B, Moore C (2014) The link between multiple sclerosis and depression. Nat Rev Neurol 10:507-517. CrossRef Medline
Fischer M, Kaech S, Wagner U, Brinkhaus H, Matus A (2000) Glutamate receptors regulate actin-based plasticity in dendritic spines. Nat Neurosci 3:887-894. CrossRef Medline

Fragale JE, Khariv V, Gregor DM, Smith IM, Jiao X, Elkabes S, Servatius RJ, Pang KC, Beck KD (2016) Dysfunction in amygdala-prefrontal plasticity and extinction-resistant avoidance: a model for anxiety disorder vulnerability. Exp Neurol 275:59-68. CrossRef Medline

Galic MA, Riazi K, Henderson AK, Tsutsui S, Pittman QJ (2009) Viral-like brain inflammation during development causes increased seizure susceptibility in adult rats. Neurobiol Dis 36:343-351. CrossRef Medline

Giuliani F, Hader W, Yong VW (2005) Minocycline attenuates T cell and microglia activity to impair cytokine production in T cell-microglia interaction. J Leukoc Biol 78:135-143. CrossRef Medline

Grabert K, Michoel T, Karavolos MH, Clohisey S, Baillie JK, Stevens MP, Freeman TC, Summers KM, McColl BW (2016) Microglial brain region-dependent diversity and selective regional sensitivities to aging. Nat Neurosci 19:504-516. CrossRef Medline

Haji N, Mandolesi G, Gentile A, Sacchetti L, Fresegna D, Rossi S, Musella A, Sepman H, Motta C, Studer V, De Chiara V, Bernardi G, Strata P, Centonze D (2012) TNF-alpha-mediated anxiety in a mouse model of multiple sclerosis. Exp Neurol 237:296-303. CrossRef Medline

Haka AS, Grosheva I, Chiang E, Buxbaum AR, Baird BA, Pierini LM, Maxfield FR (2009) Macrophages create an acidic extracellular hydrolytic compartment to digest aggregated lipoproteins. Mol Biol Cell 20:4932-4940. CrossRef Medline

Haka AS, Barbosa-Lorenzi VC, Lee HJ, Falcone DJ, Hudis CA, Dannenberg AJ, Maxfield FR (2016) Exocytosis of macrophage lysosomes leads to digestion of apoptotic adipocytes and foam cell formation. J Lipid Res 57:980-992. CrossRef Medline

Hanse E, Seth H, Riebe I (2013) AMPA-silent synapses in brain development and pathology. Nat Rev Neurosci 14:839-850. CrossRef Medline

Heiman M, Schaefer A, Gong S, Peterson JD, Day M, Ramsey KE, SuárezFariñas M, Schwarz C, Stephan DA, Surmeier DJ, Greengard P, Heintz N (2008) A translational profiling approach for the molecular characterization of CNS cell types. Cell 135:738-748. CrossRef Medline

Heppner FL, Greter M, Marino D, Falsig J, Raivich G, Hovelmeyer N, Waisman A, Rülicke T, Prinz M, Priller J, Becher B, Aguzzi A (2005) Experimental autoimmune encephalomyelitis repressed by microglial paralysis. Nat Med 11:146-152. CrossRef Medline

Hoshiko M, Arnoux I, Avignone E, Yamamoto N, Audinat E (2012) Deficiency of the microglial receptor CX3CR1 impairs postnatal functional development of thalamocortical synapses in the barrel cortex. J Neurosci 32:15106-15111. CrossRef Medline

Hristovska I, Pascual O (2015) Deciphering resting microglial morphology and process motility from a synaptic prospect. Front Integr Neurosci 9:73. CrossRef Medline

Hubert GW, Li C, Rainnie DG, Muly EC (2014) Effects of stress on AMPA receptor distribution and function in the basolateral amygdala. Brain Struct Funct 219:1169-1179. CrossRef Medline

Kerchner GA, Nicoll RA (2008) Silent synapses and the emergence of a postsynaptic mechanism for LTP. Nat Rev Neurosci 9:813-825. CrossRef Medline

Kettenmann H, Kirchhoff F, Verkhratsky A (2013) Microglia: new roles for the synaptic stripper. Neuron 77:10-18. CrossRef Medline

Kim HJ, Cho MH, Shim WH, Kim JK, Jeon EY, Kim DH, Yoon SY (2017) Deficient autophagy in microglia impairs synaptic pruning and causes social behavioral defects. Mol Psychiatry 22:1576-1584. CrossRef Medline

Kipnis J (2016) Multifaceted interactions between adaptive immunity and the central nervous system. Science 353:766-771. CrossRef Medline

Kuwabara T, Ishikawa F, Kondo M, Kakiuchi T (2017) The role of IL-17 and related cytokines in inflammatory autoimmune diseases. Mediators Inflamm 2017:3908061. CrossRef Medline

Liddelow SA, Guttenplan KA, Clarke LE, Bennett FC, Bohlen CJ, Schirmer L, Bennett ML, Münch AE, Chung WS, Peterson TC, Wilton DK, Frouin A, Napier BA, Panicker N, Kumar M, Buckwalter MS, Rowitch DH, Dawson VL, Dawson TM, Stevens B, et al. (2017) Neurotoxic reactive astrocytes are induced by activated microglia. Nature 541:481-487. CrossRef Medline

Madore C, Joffre C, Delpech JC, De Smedt-Peyrusse V, Aubert A, Coste L, Layé S, Nadjar A (2013) Early morphofunctional plasticity of microglia 
in response to acute lipopolysaccharide. Brain Behav Immun 34:151-158. CrossRef Medline

Masneuf S, Lowery-Gionta E, Colacicco G, Pleil KE, Li C, Crowley N, Flynn S, Holmes A, Kash T (2014) Glutamatergic mechanisms associated with stress-induced amygdala excitability and anxiety-related behavior. Neuropharmacology 85:190-197. CrossRef Medline

Morrison HW, Filosa JA (2013) A quantitative spatiotemporal analysis of microglia morphology during ischemic stroke and reperfusion. J Neuroinflammation 10:4. CrossRef Medline

Norden DM, Trojanowski PJ, Villanueva E, Navarro E, Godbout JP (2016) Sequential activation of microglia and astrocyte cytokine expression precedes increased iba-1 or GFAP immunoreactivity following systemic immune challenge. Glia 64:300-316. CrossRef Medline

Ohgoh M, Hanada T, Smith T, Hashimoto T, Ueno M, Yamanishi Y, Watanabe M, Nishizawa Y (2002) Altered expression of glutamate transporters in experimental autoimmune encephalomyelitis. J Neuroimmunol 125:170-178. CrossRef Medline

Ousman SS, Tomooka BH, van Noort JM, Wawrousek EF, O'Connor KC, Hafler DA, Sobel RA, Robinson WH, Steinman L (2007) Protective and therapeutic role for alphaB-crystallin in autoimmune demyelination. Nature 448:474-479. CrossRef Medline

Packard MG, Gabriele A (2009) Peripheral anxiogenic drug injections differentially affect cognitive and habit memory: role of basolateral amygdala. Neuroscience 164:457-462. CrossRef Medline

Padival M, Quinette D, Rosenkranz JA (2013) Effects of repeated stress on excitatory drive of basal amygdala neurons in vivo. Neuropsychopharmacology 38:1748-1762. CrossRef Medline

Paolicelli RC, Bolasco G, Pagani F, Maggi L, Scianni M, Panzanelli P, Giustetto M, Ferreira TA, Guiducci E, Dumas L, Ragozzino D, Gross CT (2011) Synaptic pruning by microglia is necessary for normal brain development. Science 333:1456-1458. CrossRef Medline

Parkhurst CN, Yang G, Ninan I, Savas JN, Yates JR 3rd, Lafaille JJ, Hempstead BL, Littman DR, Gan WB (2013) Microglia promote learningdependent synapse formation through brain-derived neurotrophic factor. Cell 155:1596-1609. CrossRef Medline

Pollak Y, Orion E, Goshen I, Ovadia H, Yirmiya R (2002) Experimental autoimmune encephalomyelitis-associated behavioral syndrome as a model of 'depression due to multiple sclerosis.' Brain Behav Immun 16: 533-543. CrossRef Medline

Rau AR, Chappell AM, Butler TR, Ariwodola OJ, Weiner JL (2015) Increased basolateral amygdala pyramidal cell excitability may contribute to the anxiogenic phenotype induced by chronic early-life stress. J Neurosci 35:9730-9740. CrossRef Medline

Riazi K, Galic MA, Kentner AC, Reid AY, Sharkey KA, Pittman QJ (2015) Microglia-dependent alteration of glutamatergic synaptic transmission and plasticity in the hippocampus during peripheral inflammation. J Neurosci 35:4942-4952. CrossRef Medline

Ridley AJ (1994) Membrane ruffling and signal transduction. Bioessays 16: 321-327. CrossRef Medline

Rusakov DA, Stewart MG, Korogod SM (1996) Branching of active dendritic spines as a mechanism for controlling synaptic efficacy. Neuroscience 75:315-323. CrossRef Medline

Sah P, Faber ES, Lopez De Armentia M, Power J (2003) The amygdaloid complex: anatomy and physiology. Physiol Rev 83:803-834. CrossRef Medline

Sanz E, Yang L, Su T, Morris DR, McKnight GS, Amieux PS (2009) Celltype-specific isolation of ribosome-associated mRNA from complex tissues. Proc Natl Acad Sci U S A 106:13939-13944. CrossRef Medline

Schafer DP, Lehrman EK, Kautzman AG, Koyama R, Mardinly AR, Yamasaki R, Ransohoff RM, Greenberg ME, Barres BA, Stevens B (2012) Microglia sculpt postnatal neural circuits in an activity and complementdependent manner. Neuron 74:691-705. CrossRef Medline

Schafer DP, Lehrman EK, Stevens B (2013) The "quad-partite" synapse: microglia-synapse interactions in the developing and mature CNS. Glia 61:24-36. CrossRef Medline

Schneider CA, Rasband WS, Eliceiri KW (2012) NIH image to ImageJ: 25 years of image analysis. Nat Methods 9:671-675. CrossRef Medline

Shekhar A, Truitt W, Rainnie D, Sajdyk T (2005) Role of stress, corticotrophin releasing factor (CRF) and amygdala plasticity in chronic anxiety. Stress 8:209-219. CrossRef Medline
Shemer A, Erny D, Jung S, Prinz M (2015) Microglia plasticity during health and disease: an immunological perspective. Trends Immunol 36:614624. CrossRef Medline

Sierra A, Tremblay MÈ, Wake H (2014) Never-resting microglia: physiological roles in the healthy brain and pathological implications. Front Cell Neurosci 8:240. CrossRef Medline

Singh RK, Barbosa-Lorenzi VC, Lund FW, Grosheva I, Maxfield FR, Haka AS (2016) Degradation of aggregated LDL occurs in complex extracellular sub-compartments of the lysosomal synapse. J Cell Sci 129:1072-1082. CrossRef Medline

Stellwagen D, Malenka RC (2006) Synaptic scaling mediated by glial TNFalpha. Nature 440:1054-1059. CrossRef Medline

Stellwagen D, Beattie EC, Seo JY, Malenka RC (2005) Differential regulation of AMPA receptor and GABA receptor trafficking by tumor necrosis factor-alpha. J Neurosci 25:3219-3228. CrossRef Medline

Stephan AH, Barres BA, Stevens B (2012) The complement system: an unexpected role in synaptic pruning during development and disease. Annu Rev Neurosci 35:369-389. CrossRef Medline

Suvrathan A, Bennur S, Ghosh S, Tomar A, Anilkumar S, Chattarji S (2014) Stress enhances fear by forming new synapses with greater capacity for long-term potentiation in the amygdala. Philos Trans R Soc Lond B Biol Sci 369:20130151. CrossRef Medline

Tran L, Keele NB (2016) CaMKIIalpha knockdown decreases anxiety in the open field and low serotonin-induced upregulation of GluAl in the basolateral amygdala. Behav Brain Res 303:152-159. CrossRef Medline

Tremblay ME, Lowery RL, Majewska AK (2010a) Microglial interactions with synapses are modulated by visual experience. PLoS Biol 8:e1000527. CrossRef Medline

Tremblay MÈ, Riad M, Majewska A (2010b) Preparation of mouse brain tissue for immunoelectron microscopy. J Vis Exp 41:2021. CrossRef Medline

Tremblay MÈ, Stevens B, Sierra A, Wake H, Bessis A, Nimmerjahn A (2011) The role of microglia in the healthy brain. J Neurosci 31:16064-16069. CrossRef Medline

Wake H, Moorhouse AJ, Jinno S, Kohsaka S, Nabekura J (2009) Resting microglia directly monitor the functional state of synapses in vivo and determine the fate of ischemic terminals. J Neurosci 29:3974-3980. CrossRef Medline

Wang IC, Chung CY, Liao F, Chen CC, Lee CH (2017) Peripheral sensory neuron injury contributes to neuropathic pain in experimental autoimmune encephalomyelitis. Sci Rep 7:42304. CrossRef Medline

Weinhard L, di Bartolomei G, Bolasco G, Machado P, Schieber NL, Neniskyte U, Exiga M, Vadisiute A, Raggioli A, Schertel A, Schwab Y, Gross CT (2018) Microglia remodel synapses by presynaptic trogocytosis and spine head filopodia induction. Nat Commun 9:1228. CrossRef Medline

Wildner G, Kaufmann U (2013) What causes relapses of autoimmune diseases? The etiological role of autoreactive T cells. Autoimmun Rev 12: 1070-1075. CrossRef Medline

Wu LJ, Stevens B, Duan S, MacVicar BA (2013) Microglia in neuronal circuits. Neural Plast 2013:586426. CrossRef Medline

Wu Y, Dissing-Olesen L, MacVicar BA, Stevens B (2015) Microglia: dynamic mediators of synapse development and plasticity. Trends Immunol 36:605-613. CrossRef Medline

Yamasaki R, Lu H, Butovsky O, Ohno N, Rietsch AM, Cialic R, Wu PM, Doykan CE, Lin J, Cotleur AC, Kidd G, Zorlu MM, Sun N, Hu W, Liu L, Lee JC, Taylor SE, Uehlein L, Dixon D, Gu J, et al. (2014) Differential roles of microglia and monocytes in the inflamed central nervous system. J Exp Med 211:1533-1549. CrossRef Medline

Yang G, Parkhurst CN, Hayes S, Gan WB (2013) Peripheral elevation of TNF-alpha leads to early synaptic abnormalities in the mouse somatosensory cortex in experimental autoimmune encephalomyelitis. Proc Natl Acad Sci U S A 110:10306-10311. CrossRef Medline

Zanier ER, Fumagalli S, Perego C, Pischiutta F, De Simoni MG (2015) Shape descriptors of the "never resting" microglia in three different acute brain injury models in mice. Intensive Care Med Exp 3:39. CrossRef Medline

Zito K, Scheuss V, Knott G, Hill T, Svoboda K (2009) Rapid functional maturation of nascent dendritic spines. Neuron 61:247-258. CrossRef Medline 